\title{
Triptolide inhibits Epstein-Barr nuclear antigen 1 expression by increasing sensitivity of mitochondria apoptosis of nasopharyngeal carcinoma cells
}

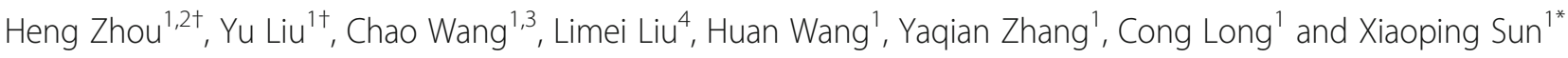

\begin{abstract}
Background: Epstein-Barr virus (EBV) is widely found in nasopharyngeal carcinoma (NPC) tissue and associated with poor prognosis of patients. EBV nuclear antigen 1 (EBNA1) is expressed in all NPC tumors and plays multiple biological roles in both virus and host cells. Triptolide is a natural product extracted from Tripterygium and shows anticancer activities. The goal of this work was to illustrate the anti-cancer effect of triptolide and elucidate a novel anti-apoptotic mechanism of EBNA1 in NPC cells encountered with triptolide.

Methods: In the present study, a CCK-8 assay was used to analyze the proliferation of NPC cells treated with triptolide in a dose- and time-dependent ways. Effects of triptolide on NPC cell cycle and apoptosis were investigated by flow cytometric analysis. EBNA1 expression in mRNA and protein levels was determined by quantitative real-time PCR and Western blot, respectively.

Results: Our results showed that triptolide effectively inhibited proliferation of NPC cells. Triptolide arrested NPC cell cycles in S phase and induced apoptosis through a caspase-9-dependent apoptosis pathway. Low-dose of triptolide reduced the half-life of EBNA1 and significantly decreased EBNA1 expression by promoting the process of proteasomeubiquitin pathway. Over-expression of EBNA1, which was independent from EBV genome, effectively attenuated the apoptosis induced by triptolide. In addition, triptolide significantly inhibited proliferations of tumors induced by EBV-positive cells in vivo. Furthermore, EBNA1 were expressed in all NPC biopsies of Chinese patients.

Conclusions: In summary, our study provides the evidence that triptolide induces EBNA1 degradation and stimulates NPC apoptosis through mitochondria apoptotic pathway. In addition, EBNA1 assists NPC cells to resist triptolide-induced apoptosis through inhibiting caspase-9-dependent apoptotic pathway.
\end{abstract}

Keywords: EBNA1, Triptolide, NPC, Apoptosis, Caspase-9

\section{Background}

Epstein-Barr virus (EBV), a $\gamma$-herpesvirus, causes asymptomatic infection in about 95\% adults in the world [1]. EBV sets up two types of infected situation in host cells, including latent infection and lytic infection [1]. EBV replication is found in both B cells and epithelial cells. The potential

\footnotetext{
* Correspondence: xsun6@whu.edu.cn

${ }^{+}$Heng Zhou and Yu Liu contributed equally to this work.

'The State Key Laboratory of Virology, Department of Pathogen Biology, School of Basic Medical Sciences, Hubei Province Key Laboratory of Allergy and Immune-related Diseases, Wuhan University, 185 Eastlake Road, Wuhan 430071, People's Republic of China

Full list of author information is available at the end of the article
}

oncogenic effect of EBV makes normal cell cancerization and eventually results in multiple human malignancies such as Hodgkin's lymphoma, Burkitt's lymphoma, nasopharyngeal carcinoma (NPC), and gastric carcinoma.

Epstein-Barr nuclear antigen 1 (EBNA1) is the only protein expressed in all three types of latent infection. Through binding to the EBV latent origin of replication (OriP) [2], EBNA1 regulates EBV's DNA synthesis and the sequential partitioning of newly synthesized viral plasmids to daughter cells [3, 4]. EBNA1 also plays an important role as an active transcription factor within viral and cellular proteins expression. EBNA1 effectively increases the activation of the family 
repeats element in OriP and promotes the expressions of latent genes of EBNAs and latent membrane proteins (LMPs) $[5,6]$. Moreover, EBNA1 can contribute to activator protein 1(AP-1) activity by inducing the transcription of the AP-1 subunits c-Jun and activating transcription factor (ATF2) [7], but decreases nuclear factor kappa B (NF-kB) activity through inhibiting the phosphorylation of the I-kappaB kinase (IKK) $\alpha / \beta$ kinase complex [8]. By binding to herpesvirusassociated ubiquitin-specific protease(USP7/HAUSP) [9] or protein kinase-casein kinase 2(CK2) [10], EBNA1 is considered to cause the destabilization of p53 [11] or promyelocytic leukemia(PML) proteins in EBV-positive cells. In addition, EBNA1 can assist malignance cells to inhibit apoptosis induced by extrinsic DNA damage drugs through destabilizing both p53 and PML proteins [10, 11].

Triptolide, a diterpene epoxide of Tripterygium extracts, has been demonstrated to perform a bioactive spectrum of anti-inflammatory, immunosuppressive, anti-fertility, anticystogenesis, and anti-cancer activities [12]. Studies also reported that triptolide could effectively kill cancer cells originated from different human organizations, including gastric [13], pancreas [14-16], brain [17], colon [18], prostate [19], blood [20], breast [21, 22], and ovary [23]. It has been reported that triptolide can stimulate the activities of caspase8, caspase-9, and caspase-3, cleave downstream PARP and activate apoptosis [24, 25]. Caspase-9-dependent mitochondrial apoptosis pathway, rather thancaspase-8- dependent pathway, has been demonstrated as the primary way of triptolide-induced cell death [12, 24]. Triptolide can covalently bind to the subunit of the transcription factor TFIIH-XPB and inhibit its downstream gene transcription [26]. Triptolide decreases the expression of O-GlcNac transferase to influence the distribution of transcription factor specificity protein 1 (SP1) from the nucleus to cytoplasm in pancreatic tumor cells $[13,16]$. Triptolide also exerts a more powerful effect against leukemia when compared with adriamycin and aclacinomycin in the clinical trial [12]. Our previous studies have indicated that triptolide could kill EBV-positive B cell lymphoma by targeting a viral oncologic protein, the latent membrane protein 1 [27]. In addition, our another study also indicated that triptolide reduced viral titers of another $\gamma$-herpesvirus, Kaposi's sarcoma-associated herpesvirus (KSHV), by decreasing expression of latency-associated nuclear antigen 1 (LANA1) [28].

In this present study, our results indicated that triptolide inhibited the proliferation of EBV-positive NPC cells, which mainly targeted in inducing EBNA1 degradation and NPC cells apoptosis in a caspase-9-dependent pathway. Importantly, EBNA1 was critical for NPC cells to resist caspase-9-dependent apoptosis induced by triptolide. Finally, we revealed that triptolide significantly inhibited the growth of xenografted tumor induced by HONE1-Akata cell in BALB/c nude mice.

\section{Methods}

\section{Cell lines and reagents}

EBV-positive NPC cell lines (HONE1/Akata, HK1/Akata, and C666-1) were kindly provided by Professor S.W. Tsao (The University of Hong Kong, Hong Kong, China). An EBV-negative NPC cell line, CNE1, was kindly given by Professor. Ya Cao (The University of Zhongnan, Chang Sha, China). Human renal embryonic 293 T cells were obtained from Professor. Zhanqiu Yang (Wuhan University, Wuhan, China).HeLa cells were kindly given by Professor Hui Li (Wuhan University, Wuhan, China). All cell lines were cultured at $37^{\circ} \mathrm{C}$ with a humidified atmosphere of $5 \% \mathrm{CO}_{2}$ in growth RPMI-1640 media (Hyclone, USA) supplemented with $10 \%$ fetal bovine serum (FBS) (Gibco, USA). G418 (400 ng/ml) was additionally added into the medium of HONE1/Akata and HK1/Akata cells to maintain the stability of the recombinant EBV genomes. HeLa and $293 \mathrm{~T}$ cells were cultured in DMEM (Hyclone, USA) containing 10\% FBS. Triptolide (Sigma, St. Louis, MO, USA), MG-132, 3-MA (Calbiochem, Billerica, MA, USA), cycloheximide (CHX) (Sigma, USA) and 12-O-tetradecanoylphorbol-13-acetate (TPA; SigmaAldrich) were dissolved in dimethylsulfoxide (DMSO), and were diluted to working concentration with PBS before use. Sodium butyrate (SB; Sigma-Aldrich) was dissolved in PBS directly.

CNE1/Akata cell line was made as described below. HONE1/Akata cells were induced to the lytic form by adding TPA $(40 \mathrm{ng} / \mathrm{ml})$ and SB $(3 \mathrm{mM})$ into culture medium for $48 \mathrm{~h}$ in order to produce virions. The cell culture medium was collected. After centrifugation at $2000 \mathrm{rpm}$ for $5 \mathrm{~min}$, the supernatant containing virions was used to infected CNE1 cells. At $24 \mathrm{~h}$ post-infection, G418 was added into the medium to get a concentration of $1000 \mathrm{ng} / \mathrm{ml}$. After $24 \mathrm{~h}$, uninfected cells would die. The living cells were continuously cultured in medium containing G418 (400 ng/ml). After stably growing for 5 generations, CNA1/ Akata cells were permitted for further experiments.

\section{Cell viability assay}

HONE1/Akata, HK1/Akata, C666-1, and CNE1 cells $(1 \times$ $10^{4}$ cells/well) were placed in 96-well plates and treated with DMSO control $(0.01 \%)$ or increasing concentrations of triptolide $(25,50,100$, or $200 \mathrm{nM})$ for 24 and $48 \mathrm{~h}$. Ten microliters of the Cell Counting Kit-8 (DOJINDO, Tokyo, Japan) reagent were then added to each well and the plates were incubated at $37^{\circ} \mathrm{C}$ for $1 \mathrm{~h}$ in dark. The optical density (OD) value was detected at an absorbance of $450 \mathrm{~nm}$ using an ELx800 microimmunoanalyser (BioTek Instruments, Inc., Winooski, VT, USA).

\section{Colony-formation assay}

HONE1/Akata, HK1/Akata, C666-1, and CNE1 cells were placed in $35 \mathrm{~mm}$ culture dishes (500 cells/dish) 
and cultured in standard medium with DMSO control $(0.01 \%)$ or triptolide $(1,2$, or $5 \mathrm{nM})$ for 2 weeks. Colony formation units were stained with $0.5 \%(w / v)$ crystal violet prepared in $0.6 \%(v / v)$ glutaraldehyde solution for $1 \mathrm{~min}$, and then cell colony in culture dishes were photographed.

\section{Cell cycle analysis}

HONE1/Akata and HK1/Akata cells were seeded in 6-well plates and treated with DMSO control $(0.01 \%)$ or triptolide $(50 \mathrm{nM})$ for $24 \mathrm{~h}$. NPC cells were digested with $0.25 \%$ EDTA-trypsin (Gbico, USA), and $2 \times 10^{5}$ cells were washed 2 times with cold PBS solution, and then resuspended with precooled $75 \%$ ethanol. After preserved at $-20{ }^{\circ} \mathrm{C}$ for $24 \mathrm{~h}$, cells were centrifuged at $1000 \mathrm{rpm}$ for $5 \mathrm{~min}$ and resuspended in $0.5 \mathrm{ml}$ cold PBS. Cells were mixed with reagent A (Multisciences, ShangHai, China). Following incubation in dark at $4{ }^{\circ} \mathrm{C}$ for $30 \mathrm{~min}$, the whole cells were analyzed immediately by a Beckman-Coulter system (EPICS Altra II; BeckmanCoulter, Fullerton, CA, USA).

\section{Apoptosis analysis}

The apoptosis levels ofHONE1/Akata and HK1/Akatacells were evaluated with Annexin V-FITC/7-AAD apoptosis detection kit (Multisciences, Shanghai, China) as manufacturer described. Briefly, cells were placed in 6-well plates and treated with vehicle control $(0.01 \%$ DMSO) or triptolide (100 or $200 \mathrm{nM}$ ) for $24 \mathrm{~h}$. Cells were digested and $2 \times 10^{5}$ cells were washed 3 times with PBS and resuspended in $500 \mu \mathrm{l}$ of $1 \times$ binding buffer, followed by adding $5 \mu \mathrm{l}$ of Annexin V-FITC and $10 \mu \mathrm{l}$ of 7-AAD, and incubating in dark at room temperature for $30 \mathrm{~min}$. The whole cells were analyzed immediately by a Beckman-Coulter system (EPICS Altra II; BeckmanCoulter, Fullerton, CA, USA).

\section{Cell transfection}

Plasmid pSG5-EBNA1 (P-ala) containing the full-length EBNA1 was constructed by Neuron Biotech Corporation (Shanghai, China). PGEM-EBNA1 (V-val) was a gift from Professor Yixin Zeng (Sun Yat-Sen University, Guangzhou, P.R. China) and described in previous study [29]. The plasmids were isolated using the plasmid DNA extraction kit (Cat No. CFLKP001-50, Chunfenglv Biomedical Technology, Beijing, P. R. China) according to the manufacturer's instructions.

EBNA1 siRNA was designed according to the previous study, and the siRNA target DNA sequence of EBNA1 was 5'-GGACTACCGACGAAGGAAC-3' [30]. The sequence was synthesized by GenePharma (Suzhou, China). For transfection, cells were placed in 6-well plates with $4 \times 10^{5}$ cells per well. The cells were transiently transfected by using X-tremeGENE HP DNA
Transfection Reagent (Roche, Basel, Switzerland) with pSG5 (the empty vector) or pSG5-EBNA1 as indicated. At $4 \mathrm{~h}$ posttransfection, cells were washed with PBS and treated with DMSO (0.01\%) or triptolide. After 24or $48 \mathrm{~h}$ incubation, cells were prepared for Western blot assay or real-time PCR.

\section{RNA isolation, reverse transcription, and real-time PCR}

TRIzol Reagent (Life, USA) was used to extract the total RNA according to the manufacturer's instructions. The concentration of RNA was determined by Nanodrop 2000 (Thermo, USA). RNAs $(1 \mu \mathrm{g})$ were reverse transcribedinto cDNA using Reverse Transcription kit (Takara, Tokyo, Japan) as the manufacturers' instructions. Expression levels of EBNA1 mRNAs were quantified by the CFX96 Real-Time PCR Detection System using an SYBR Premix Ex Taq kit (Takara, Tokyo, Japan). The primers were as follows: EBNA1 forward, 5'TCATCATCATCCGGGTCTC C-3'; EBNA1 reverse, 5'-CCTACAGGGTGGAAAAATG GC-3';GAPDH forward, 5'-GGTGGCTTCTGACTTCAAC A-3'; GAPDH reverse, 5'-GTTGCTGTAGCCAAATTCG TTGT-3'. The EBNA1 levels were normalized to the housekeeping gene GAPDH. All experiments were repeated independently 3 times.

\section{Western blot assay}

Cells treated in different conditions were harvested in RIPA lysis buffer (BeyotimeInstitute of Biotechnology, Shanghai, China) supplemented with $0.5 \%$ cocktail protease inhibitor (Roche) and $0.5 \mathrm{mMphenylmethylsulfonyl}$ fluoride (PMSF). Followed by storing on ice for $10 \mathrm{~min}$, the cell lysates were collected and sonicated for $15 \mathrm{~s}$. After centrifugation at $12,000 \times \mathrm{g}$ for $15 \mathrm{~min}$, the supernatants were collected and transferred into new tubes, and the protein concentration was measured by BCA protein assay (BioRad, USA). Equal amounts of proteins were then mixed with $5 \times$ loading buffer $(250$ nMTris-Hcl (pH 6.8), 0.5\% BPB, 50\% glycerol, 10\% SDS, $5 \% \beta$-mercaptoethanol) and boiled for $5 \mathrm{~min}$. Then the mixtures were subjected to $10 \%$ SDS-PAGE gels in running buffer and subjected to immunoblot analyses.

The primary antibodies used were as follows: GAPDH (Cat No. 10494-1-AP, 1:5000; Proteintech, Wuhan, China); $\beta$-actin (Cat No. CFLKT001, 1:10,000, Beijing Chunfenglv Biomedical Technology Co., Ltd., Beijing, China); caspase-3 (Cat No. 9668, 1:1000; Cell Signaling Technology, USA); cleaved caspase-3 (Cat No. 9664, 1:1000; Cell Signaling Technology, USA); caspase-9 polyclonal antibody (Cat No. A2636, 1:1000; ABclonal, Boston, UK); cleaved PARP-1(Cat No. sc-56,196, 1:500; Santa Cruz Biotechnology, USA); P53 (DO-1) (Cat No. sc-126, 1:500; Santa Cruz Biotechnology, USA); Lamin-A (Cat No. 4777; 1:2000, Cell Signaling Technology, USA); Beta-Tublin (Cat No. 4777; 1:3000, Cell Signaling Technology, USA). Western blot gray values were 
determined by ImageJ software (National Institutes of Health, USA).

\section{Hoechst 33,258 staining}

Cell nuclear fragmentation was examined by Hoechst 33,258 (Beyotime Biotechnology, China). HONE1/Akata cells $\left(4 \times 10^{5}\right)$ were placed in 6 -well plate with a glass slide in the well, then treated with DMSO control $(0.01 \%)$ or triptolide $(100 \mathrm{nM})$ for $24 \mathrm{~h}$. Cells were fixed for $30 \mathrm{~min}$ at room temperature by using $4 \%$ paraformaldehyde, then washed 3 times with PBS. Followed by permeabilization with $0.1 \%$ TritonX-100 in PBS at room temperature for $15 \mathrm{~min}$, cells were then washed 3 times with PBS. Then, cells were blocked with $5 \%$ bovine serum albumin (BSA) in PBS for $30 \mathrm{~min}$ and washed 3 times with PBS. Cells were stained with Hoechst 33,258 in dark for $5 \mathrm{~min}$, and washed 3 times with PBS. The slides were covered with glycerinum and observed using a fluorescence microscope.

\section{Peripheral blood mononuclear cell (PBMC) isolation}

Patient samples were obtained from Clinical Laboratory of Renmin Hospital of Wuhan University. Patients have been informed of the contents of the assay. All the selected patients were detected to carry EBV in plasma and were confirmed as EBV-positive patients. PBMC was isolated from whole blood by Ficoll-Hypaque density gradient centrifugation according to manufacturer's instructions (Sigma, USA) and cultured in RPMI 1640 containing 10\% FBS (Hyclone, USA), 1\% glutamine (Sigma, USA), and 1\% penicillin/streptomycin (Sigma, USA).

\section{Immunohistochemistry}

Immunohistochemistry was performed using antibodies against EBNA1 or cleaved caspase-3 under the manufacturer's instructions. The tissue sections were fixed with $10 \%$ neutral buffered formalin for $12 \mathrm{~h}$. After dehydration, the tissue sections were paraffin-embedded. The paraffin section was deparaffinized using xylene for $20 \mathrm{~min}$ and then permeated in gradient concentrations of alcohol. For antigen retrieval, the tissue section was boiled in citric acid (pH 6.0) for $20 \mathrm{~min}$. Endogenous peroxidase activity was quenched with $3 \% \mathrm{H}_{2} \mathrm{O}_{2}$ for $10 \mathrm{~min}$. Then the slide was blocked in goat serum for $1 \mathrm{~h}$ at room temperature, followed by incubating with primary antibodies (EBNA1, Cat No. 8329, 1:1000, Abcam, USA; cleaved caspase-3, Cat No. 9664, 1:1000; Cell Signaling Technology, USA) overnight at $4{ }^{\circ} \mathrm{C}$. After incubated for $15 \mathrm{~min}$ at room temperature with secondary antibody $\left(\mathrm{MaxVision}^{\mathrm{Tm}} \mathrm{Kits}\right.$, MXB, China) conjugated with horseradish peroxidaselabeled polymer, tissue section was incubated for $1 \mathrm{~min}$ with diaminobenzidine. The section was counterstained with hematoxylin lightly.

\section{Immunofluorescence assay}

The pre-process of immunofluorescence assay was performed as described in the part of immunohistochemistry. After incubation with primary antibody (EBNA1, Cat No. 8329,1:1000,Abcam, USA) for $30 \mathrm{~min}$ at room temperature, the slides were incubated for $50 \mathrm{~min}$ at $37{ }^{\circ} \mathrm{C}$ with the Alexa Fluor 488-conjugatedsecondary antibody (goat antimouse, cat. no. A32723, 1:100, Invitrogen, USA). The morphology of cell nuclei was observed by DAPI staining. Images were photographed and synthesized by MicroPublisher (Q-IMAGING, Canada).

\section{Animal studies}

HONE1/Akata cells $\left(1 \times 10^{7}\right)$ were inoculated subcutaneously into both flanks of 4-week-old male BALB/c nude mice (purchased from the ABSL-3 animal lab at Wuhan University). Seven days later, when tumor became to be palpable, mice (five per group) were treated with a single intraperitoneal injection of triptolide at $0.4 \mathrm{mg} / \mathrm{kg}$ or DMSO daily. After 21 days of treatment, mice were sacrificed by cervical dislocation. Mice weights and tumor sizes were measured, and tumor volume was calculated as $0.5 \times$ length $\times$ width $\times$ width. Tissue samples were collected and fixed in $10 \%$ neutral buffered formalin, embedded, and sectioned at a $5 \mu \mathrm{m}$ of thickness.

\section{Nuclear and cytoplasmic protein extraction}

HONE1/Akata cells $\left(1 \times 10^{6}\right)$ were placed in $6 \mathrm{~cm}$ plates and cultured for $48 \mathrm{~h}$. Then the cells were subjected to extraction of nuclear and cytoplasmic proteins by NEPER Nuclear and Cytoplasmic Extraction Reagents (Thermo, USA). The detailed process of extraction was performed according to the introduction of manufacturer. After protein concentration was determined, the nuclear and cytoplasmic proteins were mixed with $5 \times$ loading buffer and boiled for $5 \mathrm{~min}$, and subjected to Western blot assay.

\section{Immunohistochemistry analysis of EBNA1 and Ki67 expression in NPC biopsies}

All the NPC biopsies and correlative clinical data were obtained from the department of pathology, Renmin Hospital of Wuhan University. Expression of EBNA1 and Ki67 was analyzed by two pathologists, Dr. Heng Zhou and Dr. Wen Liu (department of pathology, Renmin Hospital of Wuhan University).

\section{Statistical analysis}

Data were shown as the mean \pm standard deviation (mean $\pm \mathrm{SD}$ ) and analyzed by Student's t-test using GraphPad Prism for Windows version 5.0 (GraphPad Software, La Jolla, USA), and $p$-values $<0.05$ were considered as statistically significant. 


\section{Results}

Triptolide effectively suppresses proliferation of NPC cells To determine whether triptolide decreases cell viabilities of NPC cells, 5 kinds of NPC cells were treated with triptolide for $24 \mathrm{~h}$ or $48 \mathrm{~h}$ in a dose-dependent manner. As shown in Fig. 1a-e, triptolide significantly inhibited cell viabilities of C666-1, HONE1/Akata, HK1/Akata, CNE1/Akata and CNE1 cells in comparison with the cells treated with DMSO control (0.01\%). The $\mathrm{IC}_{50}$ of C666-1, HONE1/ Akata, HK1/Akata, CNE1/Akata and CNE1 were 55.43, 76.56, 1.12, 11.04 and $10.66 \mathrm{nM}$, respectively. To further confirm the above results, colony formation assay was performed. Four kinds of EBV-positive NPC cells were placed in $35 \mathrm{~mm}$ culture dishes, treated with DMSO control $(0.01 \%)$ or triptolide $(1,2$, or $5 \mathrm{nM})$ for 2 weeks, and stained with crystal violet. As shown in Fig. 1f, low concentration of triptolide remarkably reduced colony formation at both colony size and numbers. These results strongly suggest triptolide effectively inhibits proliferations of both EBVnegative and EBV-positive NPC cells.

\section{Triptolide arrests cell cycles in S phase}

To determine whether triptolide affects cell cycles of NPC cells, HONE1/Akata and HK1/Akata cells were treated with DMSO control (0.01\%) or triptolide (50 nM) for $24 \mathrm{~h}$ and then harvested. The cell cycle distributions were analyzed by flow cytometry (Fig. 2a, b). As shown in Fig. 2c, the cell cycles of HONE1/Akata and HK1/Akata were all arrested in $S$ phase. The fractions of S phase cells of HONE1/Akata and HK1/Akata were increased by $29.0 \%$ and $16.8 \%$ respectively when treated with triptolide $(50 \mathrm{nM})$. These results reveal that triptolide arrests cell cycles in $\mathrm{S}$ phase effectively.

\section{Triptolide induces mitochondrial apoptosis in NPC cells}

To examine the apoptotic effect induced by triptolide, NPC cells were treated with DMSO control $(0.01 \%)$ or triptolide (100 nM) for $24 \mathrm{~h}$ or $48 \mathrm{~h}$, respectively. As shown in Fig. 2d, treatment of HONE1/Akata and HK1/Akata cells with triptolide resulted in apoptosis in a time-dependent manner. In addition, western blotting was performed to detect the expression of several apoptosis-related proteins. As shown in Fig. 2e, triptolide decreased expression of caspase- 9 and increased expression of p53, cleaved caspase3 and cleaved PARP-1 in EBV-positive HONE1/Akata, HK1/Akata, C666-1 and EBV-negative NPC CNE1cells. All these results indicate that triptolide induces apoptosis of NPC cells.

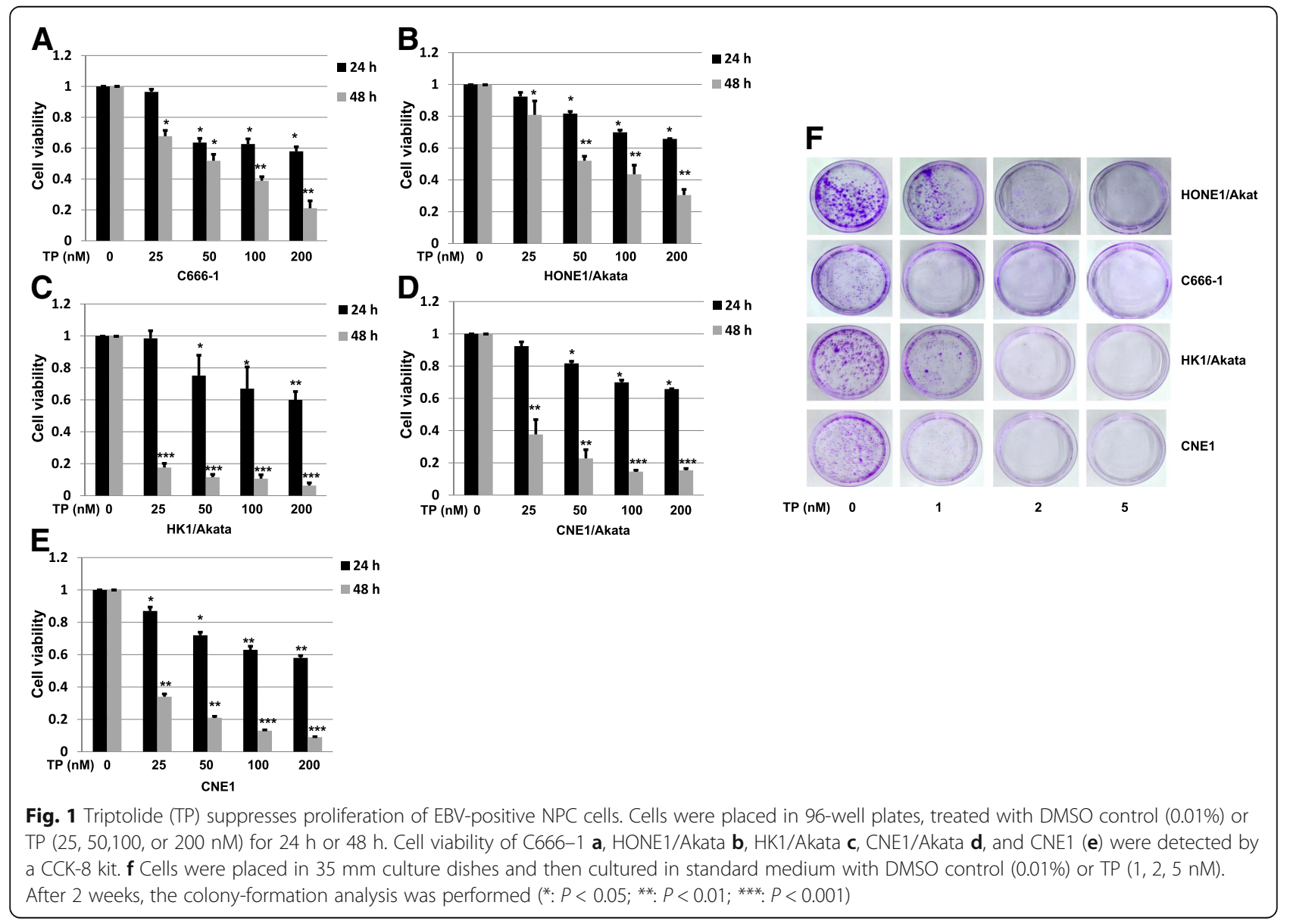




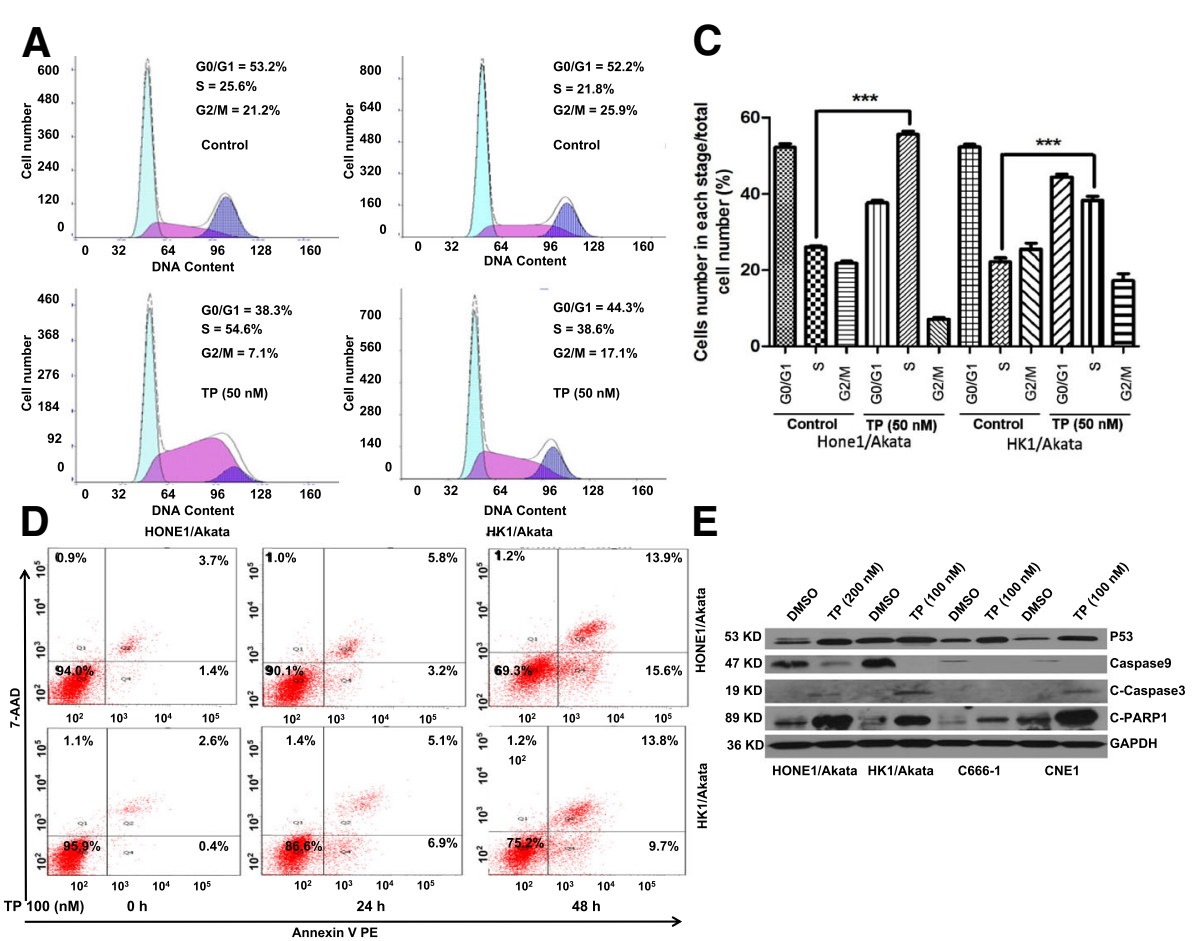

Fig. 2 TP arrests cell cycles and induces apoptosis in EBV-positive NPC cells. a HONE1/Akata and (b) HK1/Akata cells were treated with DMSO control $(0.01 \%)$ or TP $(50 \mathrm{nM})$ for $24 \mathrm{~h}$. The distribution of cell cycle was determined by flow cytometry. $\mathbf{c}$ The cell cycle distribution is quantified by the bar graphs. $\mathbf{d}$ HONE1/Akata and HK1/Akata cells were treated with DMSO control (0.01\%) or TP (100 nM) for 24 hand 48 h, respectively. Apoptosis assay was performed by flow cytometry. e Four kinds of NPC cells were treated with DMSO control (0.01\%) or TP for $48 \mathrm{~h}$, protein expression was determined by Western blotting assay. ( ${ }^{*}: P<0.05$; ${ }^{* *}: P<0.01$; ${ }^{* *}: P<0.001$ )

Triptolide decreases expression of EBNA1 in NPC cell lines Our previous work demonstrated that triptolide decreases LANA1 expression in KSHV-positive primary effusion lymphoma [28]. Therefore, we next wanted to examine whether triptolide affects the expression of EBNA1 in EBV-positive NPC cells. Three different EBV-positive NPC cell lines (HONE1/Akata, HK1/ Akata, and C666-1) were treated with DMSO control $(0.01 \%)$ or triptolide $(100$ or $200 \mathrm{nM})$ for $48 \mathrm{~h}$. As shown in Fig. $3 \mathrm{a}-\mathrm{d}$, the expression of EBNA1 in HONE1/Akata, HK1/Akata, and C666-1 was significantly decreased by $68.21 \%, 70.09 \%$ and $65.37 \%$ when treated with $200 \mathrm{nM}$ triptolide. After that, we detected whether triptolide affects the transient expression of EBNA1, which is independent of EBV genome. PSG5-EBNA1(P-ala) plasmids were transfected into EBV-negative $293 \mathrm{~T}$ and HeLa cells, and EBNA1(V-val) plasmids were transfected into CNE1 and CNE1/Akata cells for $4 \mathrm{~h}$, then cells were treated with triptolide for another $44 \mathrm{~h}$. As shown in Fig. $3 \mathrm{e}-\mathrm{h}$, triptolide significantly decreased the expressions of EBNA1(P-ala) and EBNA1(V-val). All these results suggest that triptolide decreases EBNA1 expression.
Triptolide reduces stability and half-life of EBNA1 and induces proteasomal degradation of EBNA1

The decrease of protein levels may be due to the suppression of mRNA levels, so we next detected the effects of triptolide on the transcriptional levels of EBNA1. HONE1/ Akata, HK1/Akata, and C666-1 cells were treated with $0.01 \%$ DMSO control or triptolide $(100 \mathrm{nM})$ for $24 \mathrm{~h}$. As shown in Fig. 4a, interestingly, triptolide increased EBNA1 transcriptional levels to varying degrees. Since triptolide increased EBNA1 mRNA levels, we wondered whether triptolide decreases protein stability or posttranslational modification of EBNA1. To determine whether triptolide affects proteasome pathway in EBV-positive NPC cells, HK1/Akata and HONE1/Akata were treated with DMSO control $(0.01 \%)$ or triptolide (100 or $200 \mathrm{nM})$ for $48 \mathrm{~h}$ in the absence or presence of proteasome inhibitor MG-132 $(50 \mu \mathrm{M})$ for $12 \mathrm{~h}$. In addition, HK1/Akata and HONE1/ Akata were treated with DMSO control $(0.01 \%)$ or triptolide (100 or $200 \mathrm{nM}$ ) for $24 \mathrm{~h}$ in the absence or presence of proteasome inhibitor MG-132 $(50 \mu \mathrm{M})$ for $24 \mathrm{~h}$. Cells were harvested and the expression of EBNA1 was analyzed by western blotting. As shown in Fig. 4b, c, MG132 attenuated triptolide-induced EBNA1 degradation in HK1/Akata and HONE1/Akata cells. As shown in Fig. 4d, e, MG132 

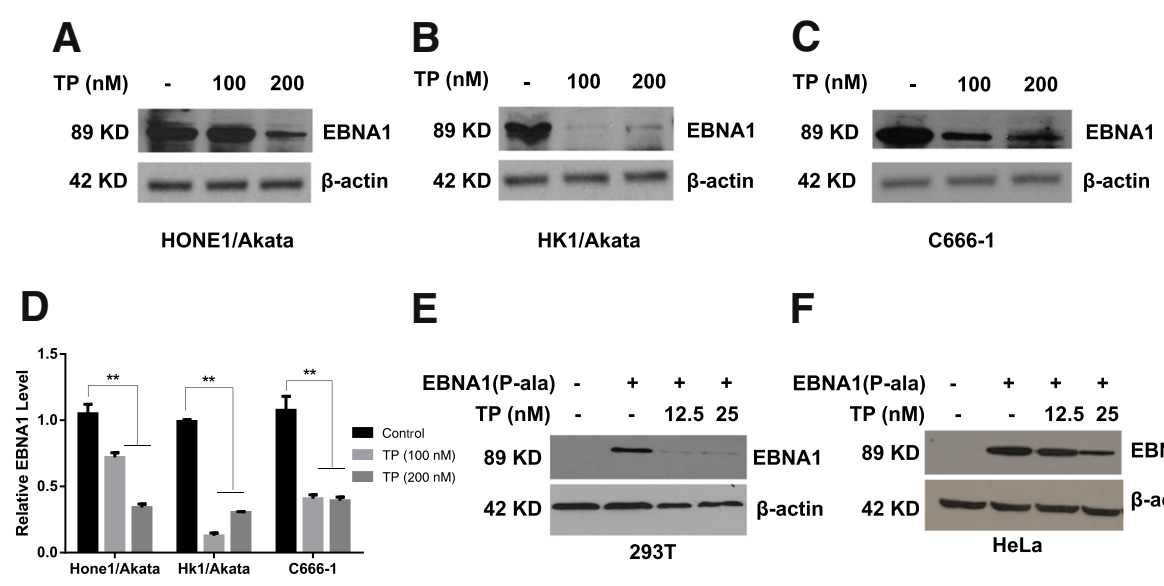

E
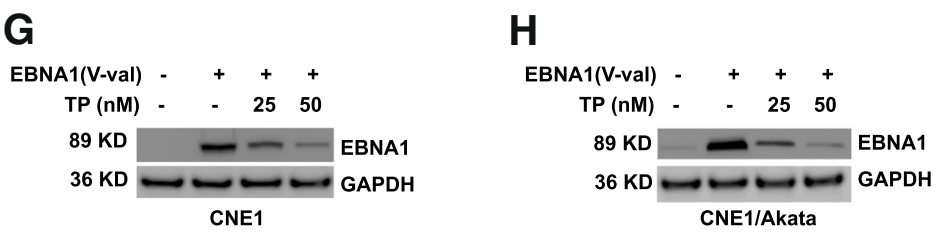

Fig. 3 TP decreases the expression of EBNA1. a HONE1/Akata, b HK1/Akata, and (c) C666-1 cells were treated with DMSO (0.01\%) or TP (100 or $200 \mathrm{nM}$ ) for $48 \mathrm{~h}$, respectively. Fig. d showed the quantified bar graph of EBNA1 expression in NPC cell lines treated with TP. e $293 \mathrm{~T}$ or (f) HeLa cells were transfected with pSG5 or pSG5-EBNA1(P-ala) for 4 h, followed by treatment with TP (12.5 or 25 nM) for 44 h. g CNE1 and (h) CNE1/ Akata were transfected with pGEM or pGEM-EBNA1(V-val) for $4 \mathrm{~h}$, followed by $44 \mathrm{~h}$ treatment with TP ( 25 or $50 \mathrm{nM})$. Whole-cell extracts were prepared and subjected to Western blot analysis

increased EBNA1 expression in the presence or absence of triptolide both in HK1/Akata and HONE1/Akata cells. To determine whether triptolide induces EBNA1 degradation through autophagy pathway, CNE1/Akata cells were treated with triptolide $(100 \mathrm{nM})$ in the presence or absence of 3-MA (10 mM). As shown in Fig. 4f 3-MA did not attenuate the inhibitory effect of triptolide on the expression level of EBNA1 in CNE1/Akata cells. These results suggested that triptolide induces the degradation of EBNA1 through a proteasome-ubiquitin pathway.

We then supposed whether triptolide affects EBNA1 stability. Hence, we used CHX as an adjuvant to investigate it. HONE1/Akata and HK1/Akata cells were treated with DMSO $(0.01 \%)$ or triptolide $(100 \mathrm{nM})$ in the presence of CHX $(25 \mu \mathrm{g} / \mathrm{ml})$ in a time-dependent manner. As shown in Fig. $4 \mathrm{~g}$, h, the group treated with both $\mathrm{CHX}$ and triptolide accelerated degradation of EBNA1 in comparison with the group treated with $\mathrm{CHX}$ alone, which indicated that triptolide reduces the half-life of EBNA1 and decreases its stability directly. In addition, the expression of EBNA1 after triptolide treatment over time was tested. As shown in Fig. $4 \mathrm{i}$, $\mathrm{j}$, when treated with triptolide, EBNA1 protein levels were increased at $12 \mathrm{~h}$ in HONE1/Akata and HK1/Akata, and then decreased with the passage of time. All these results show that triptolide inhibits EBNA1 expression through impairing the stability of EBNA1 and inducing proteasomal degradation of EBNA1.

\section{Exogenous EBNA1 attenuates the triptolide-induced mitochondrial apoptosis}

EBNA1 plays an anti-apoptosis role acting on USP7/ HAUSP and CK2 pathways [9-11], thus we wondered whether EBNA1 could inhibit apoptosis effects induced by triptolide in NPC cells. Briefly, pSG5-EBNA1(P-ala) plasmids were transfected into HONE1/Akata, HK1/Akata and CNE1 cells for $4 \mathrm{~h}$, then treated with triptolide $(100 \mathrm{nM})$ for another $44 \mathrm{~h}$. As shown in Fig. 5a, b, over-expression of EBNA1 attenuated the expression of several apoptosis-related proteins, including cleaved PARP-1, cleaved caspase-3, and cleaved caspase-9. To determine whether EBNA1 attenuates apoptotic effect outside the context of the EBV genome, the above experiments were repeated in an EBV-negative NPC cell line-CNE1 and human epithelial cervical cancer HeLa cells. Similar results were obtained and shown in Fig. 5c, d.

In addition, dose-dependent pSG5-EBNA1 (P-ala) transfections in HONE1/Akata and HeLa cells were complemented to confirm the anti-apoptosis effect of EBNA1. As shown in Fig. 5e, f, EBNA1 possessed the biological property to restrain apoptosis in a dose-dependent manner in HONE1/Akata and HeLa cells. EBNA1 (V-val), the dominant subtype in Asian [31,32], was reported to be found in tumor tissues of Asian NPC patients. Hence, pGEMEBNA1(V-val) or control plasmid was transfected into 

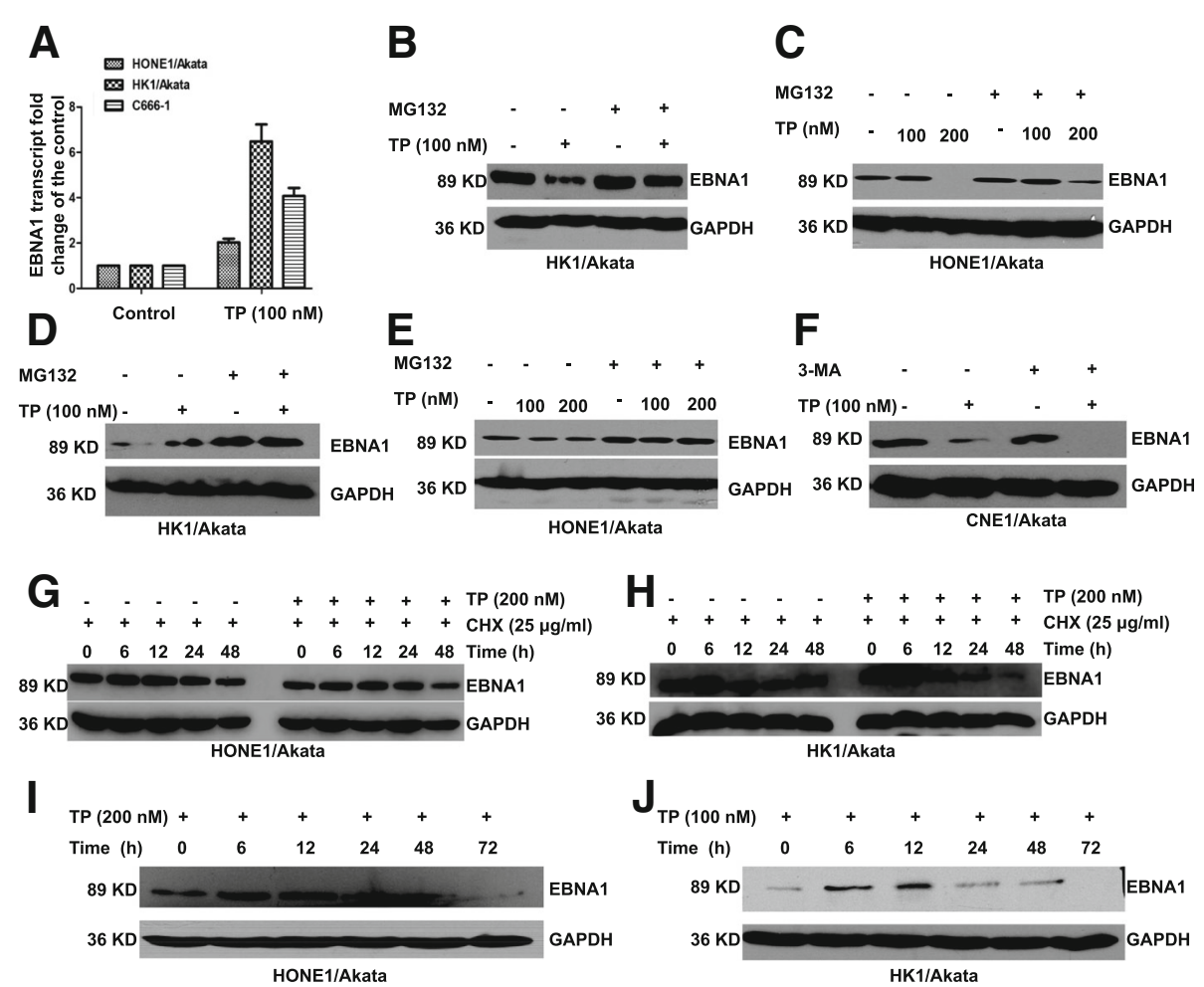

Fig. 4 TP reduces the half-life of EBNA1 and induces proteasomal degradation of EBNA1. a HONE1/Akata, HK1/Akata, and C666-1 cells were treated with DMSO (0.01\%) or TP (100 nM) for $24 \mathrm{~h}$. Transcriptional levels of EBNA1 were examined by the real-time PCR. b HK1/Akata and (c) HONE1/Akata cells were treated for $48 \mathrm{~h}$ with DMSO control $(0.01 \%)$ or TP $(100 \mathrm{nM})$ in the absence or presence of proteasome inhibitor MG-132 (50 $\mu \mathrm{M})$ for the last $12 \mathrm{~h}$. $\mathbf{d}$ HK1/Akata and (e) HONE1/Akata cells were treated with DMSO control (0.01\%) or TP (100 nM) in the absence or presence of proteasome inhibitor MG-132 (50 $\mu \mathrm{M})$ for $24 \mathrm{~h}$. f CNE1/Akata cells were treated with DMSO control (0.01\%) or TP (100 nM) in the absence or presence of the autophagy inhibitor 3-MA (10 mM). $\mathbf{g}$ HONE1/Akata and (h) HK1/Akata cells were treated with DMSO (0.01\%) or TP $(200 \mathrm{nM})$ in the presence of CHX (25 $\mu \mathrm{g} / \mathrm{ml})$ for indicated times. i HONE1/Akata and (j) HK1/Akata cells were treated with $0.01 \%$ DMSO or TP for 6, 12, 24, 48, and 72 h, respectively. Whole-cell extracts were prepared and subjected to Western blot analysis

CNE1 and CNE1/Akata cells in the presence or absence of triptolide (100 nM). Over-expression of EBNA1 (V-val) significantly attenuated mitochondrial apoptosis-associated active protein expressions, including cleaved PARP-1, cleaved caspase-3, and cleaved caspase-9 (Fig. 5g, h).

Furthermore, EBNA1 was knockdown to evaluate its anti-apoptosis effects. EBNA1 siRNA or control siRNA was respectively transfected into HONE1/Akata or C666-1cells. After $24 \mathrm{~h}$ transfection, cells were then treated with DMSO $(0.01 \%)$ or triptolide $(100 \mathrm{nM})$ for $48 \mathrm{~h}$. As shown in Fig. 5i, j, knockdown of EBNA1 significantly enhanced triptolide-induced caspase- 9 apoptotic pathway. These results suggest that EBNA1 could inhibit triptolide-induced mitochondrial apoptosis in NPC cells.

\section{Exogenous EBNA1 attenuates the inhibitory and apoptotic effects of triptolide}

Previous studies have suggested that targeting on EBNA1 is an effective strategy of NPC therapy [33-35]. To determine if EBNA1 reduction contributes to the killing effect of triptolide, CNE1 and CNE1/Akata cells were transfected with control plasmids or EBNA1 plasmids (P-ala or V-val) for $4 \mathrm{~h}$, and then treated with triptolide $(100 \mathrm{nM})$ for 24 or $48 \mathrm{~h}$. The CCK- 8 assay was used to test the cell viability. As shown in Fig. 6a-d, over-expression of EBNA1 (P-ala or $\mathrm{V}$-val) attenuated the inhibitory of triptolide significantly. These results suggest that decreased EBNA1 expression substantially contributes to the killing effect of triptolide on NPC cells.

To further verify the anti-apoptotic effect of EBNA1, Hoechst staining was used to observe anti-apoptosis effects of EBNA1 in HONE1/Akata cells (Fig. 6e). As shown in Fig. 6f, the average apoptotic rate degraded from $48.8 \%$ in the group of treatment with triptolide alone to $29.5 \%$ in the group of transfection with pSG5-EBNA1. Above all, these results may indicate that EBV attenuates triptolideinduced NPC cells death through the anti-apoptosis effect of EBNA1. 


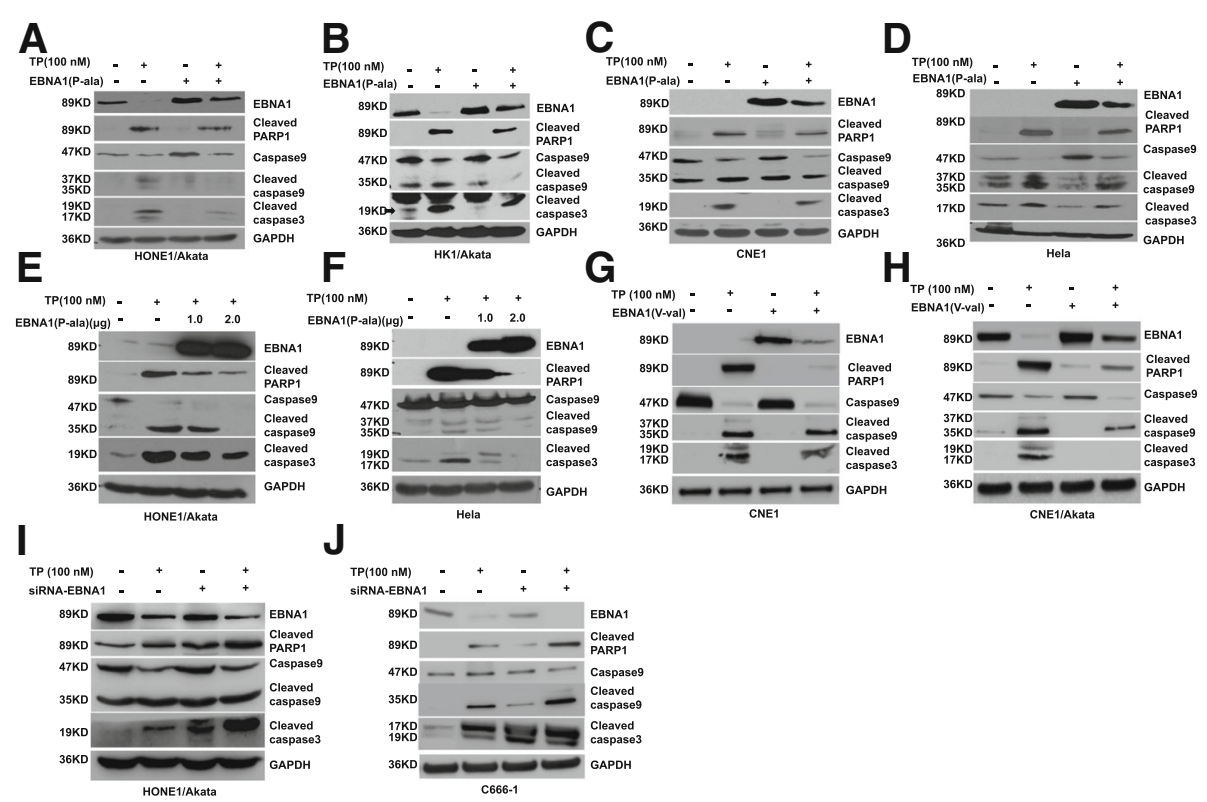

Fig. 5 Over-expression of EBNA1 attenuates mitochondrial apoptosis induced by TP. a HONE1/Akata, b HK1/Akata, c CNE1, and (d) HeLa cells were transfected with pSG5-EBNA1(P-ala) for $4 \mathrm{~h}$, followed by treatment with DMSO control (0.01\%) or TP(100 nM) for 44 h, respectively. e HONE1/Akata and (f) Hela cells were transfected with pSG5-EBNA1(P-ala) at indicated concentrations for 4 h, followed by treatment with DMSO control (0.01\%) or TP(100 nM) for 44 h, respectively. g CNE1 and (h) CNE/Akata cells were transfected with pGEM-EBNA1(V-val) for 4 h, then treated with DMSO control (0.01\%) or TP (100 nM) for 44 h, respectively. i HONE1/Akata and (j) C666-1cells were transfected with EBNA1 siRNA for $4 \mathrm{~h}$, then treated with DMSO control $(0.01 \%)$ or TP $(100 \mathrm{nM})$, respectively. Whole-cell extracts were prepared and subjected to Western blot analysis

\section{Low-toxicity of triptolide decreases the expression of EBNA1 in PBMCs}

To examine whether a safe concentration of triptolide decreases the expression of EBNA1, PBMCs were cultured in 96-well plate and treated with a dose-dependent triptolide (0, 20, 40, 80 and $120 \mathrm{nM}$ ) for $96 \mathrm{~h}$. As shown in Fig. 7a, triptolide significantly inhibited cell viability of PBMCs at $120 \mathrm{nM}$. Hence, a safe and low-toxicity concentration of $40 \mathrm{nM}$ was selected to determine if triptolide decreased expression of EBNA1. PBMCs were treated with $40 \mathrm{nM}$ triptolide for $96 \mathrm{~h}$ and then harvested for Western blotting. As shown in Fig. 7b, d, expression of EBNA1was decreased significantly in different donors. To determine whether the safe concentration of triptolide decreases the expression of EBNA1 in NPC cells, HONE1/Akata, CNE1/Akata, CNE1/Akata, and C6661 cells were treated with $40 \mathrm{nM}$ triptolide for $96 \mathrm{~h}$. Western blotting showed that the expression of EBNA1 was decreased significantly in all NPC cell lines (Fig. 7c, e). In addition, cells treated with $40 \mathrm{nM}$ of triptolide significantly inhibited the cell viability of NPC cells at both $48 \mathrm{~h}$ and $96 \mathrm{~h}$ (Fig. 7f). These results indicate that the safe concentration of triptolide reduces EBNA1 expression in EBV positive cells.

\section{Triptolide inhibits proliferation of NPC cell-induced tumor in vivo}

Since our above results indicated that triptolide inhibits proliferation of NPC cells in vitro, effects of triptolide in vivo were also examined by using BALB/c nude mice. To study whether triptolide influences growth of NPC in BALB/c mice, $1 \times 10^{7} \mathrm{HONE} 1 /$ Akata cells were injected subcutaneously into flanks of the mice. When tumor had grown to be palpable ( 7 days later), the mice were treated with $0.4 \mathrm{mg} / \mathrm{kg}$ triptolide or DMSO daily via intraperitoneal injection. After 15 days, mice were euthanized and tumors were measured and weighed. As shown in Fig. 8a-c, representative photos (8A), tumor volumes (8B) and tumor weights $(8 C)$ suggested that triptolide could inhibit the growth of tumors. To determine the mechanism how triptolide suppresses the growth of tumor, the expression and distribution of EBNA1 and cleaved caspase-3 in the tumor tissues were analyzed by immunohistochemical assay. As shown in Fig. 8d, the tissue slides of triptolide group showed stronger positive signals of cleaved caspase-3 than those of control slides. Conversely, EBNA1 positive signals in the triptolide group were weaker than the slides in the control group. In addition, western blotting assay was performed to detect expression of EBNA1 and the associated apoptotic proteins. As shown in Fig. 8e, EBNA1 expression was decreased in triptolide group compared with control group. Triptolide increased the expression of associated apoptotic proteins (cleaved PARP1, cleaved caspase-3, and cleaved caspase-9) in tumor tissues. 

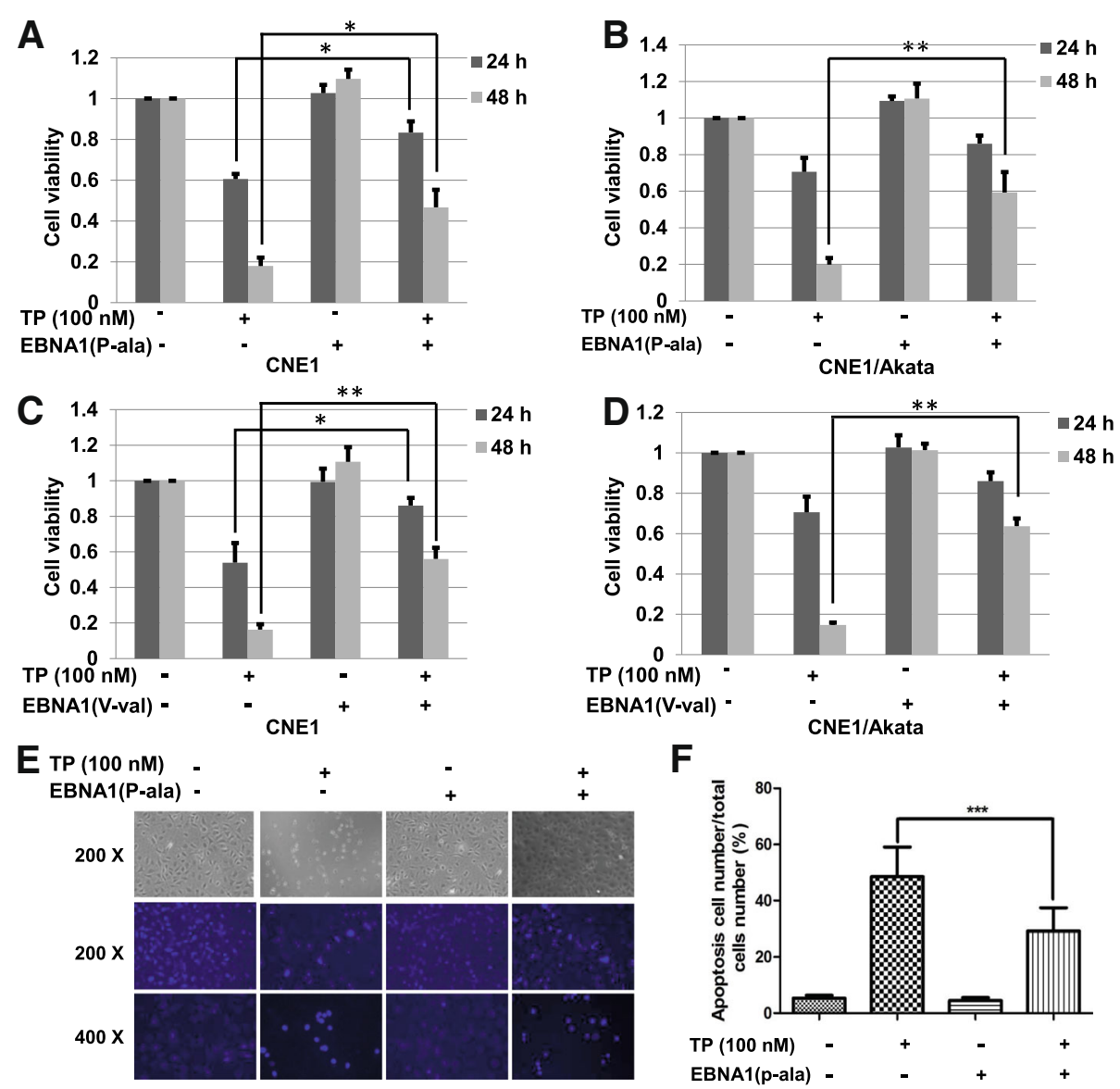

Fig. 6 Over-expression of EBNA1 attenuates TP-induced cell killing and apoptotic effect. a CNE1 and (b) CNE1/Akata cells were transfected with pSG5-EBNA1 (P-ala) or pSG5 for $4 \mathrm{~h}$, and treated with TP $(100 \mathrm{nM})$ for $24 \mathrm{~h}$ or $48 \mathrm{~h}$. c CNE1 and (d) CNE1/Akata cells were transfected with pGEMEBNA1(V-val) or pGEM for $4 \mathrm{~h}$, and treated with TP (100 nM) for $24 \mathrm{~h}$ or $48 \mathrm{~h}$. Cell viability of NPC cells were detected by a CCK-8 assay. e HONE1/ Akata cells were treated with DMSO control $(0.01 \%)$ or TP (100 nM) for $24 \mathrm{~h}$. After staining with Hoechst 33,258, cells were observed using a fluorescence microscope. $\mathbf{f}$ The apoptosis cell numbers were calculated, quantified, and shown by the bar graphs $\left(^{*}: P<0.05\right.$; **: $P<0.01$; ***: $P<0.001)$

These results suggest that triptolide inhibits proliferation of NPC induced by EBV-positive HONE1/Akata cells.

\section{Distribution of EBNA1 is associated with tumor growth in NPC patients}

Since the above results suggested triptolide targets EBNA1 to inhibit proliferation of EBV-positive cells and tumor growth in the animal model experiment, we continue to investigate the distribution of EBNA1 in NPC patients. Totally 43 non-keratinizing NPC biopsy tissues from patients in Renmin Hospital of Wuhan University were investigated, which included 26 undifferentiated carcinomas and 17 differentiated carcinomas (1 carcinoma/patient) (Table 1). All the chosen biopsy tissues were only EBV-positive tissues by detecting the EBV-encoded small RNA (EBER), a small RNA encoded by EBV latent infection stage (not shown). Immunofluorescence and immunohistochemistry assays were performed to detect the expression and distribution of EBNA1. Among all the EBV-positive tissues, the EBNA1 protein was expressed (100\%). However, EBNA1 was expressed in the cytoplasm of all the 43 tumor biopsies but expressed in both nuclear and cytoplasm of 10 tumor biopsies in NPC cells. Results of representative cases were shown in Fig. 9a, c. Nuclear and cytoplasmic protein extraction was performed to detect EBNA1 distribution in NPC cells. As shown in Fig. 9d, the expression of EBNA1 was observed both in nucleus and cytoplasm of HONE1/Akata cells.

The associations among sex, histological type, Ki67 expression, and EBNA1 distribution were analyzed statistically. Notably, Ki67 is a nuclear protein, which is an indicator of proliferation state of the cancer cells. Therefore, patients were divided into two groups based on the Ki67 expression. As shown in Table 1, EBNA1 distribution was independent of sex and histological type. The immunohistochemistry results revealed that low 

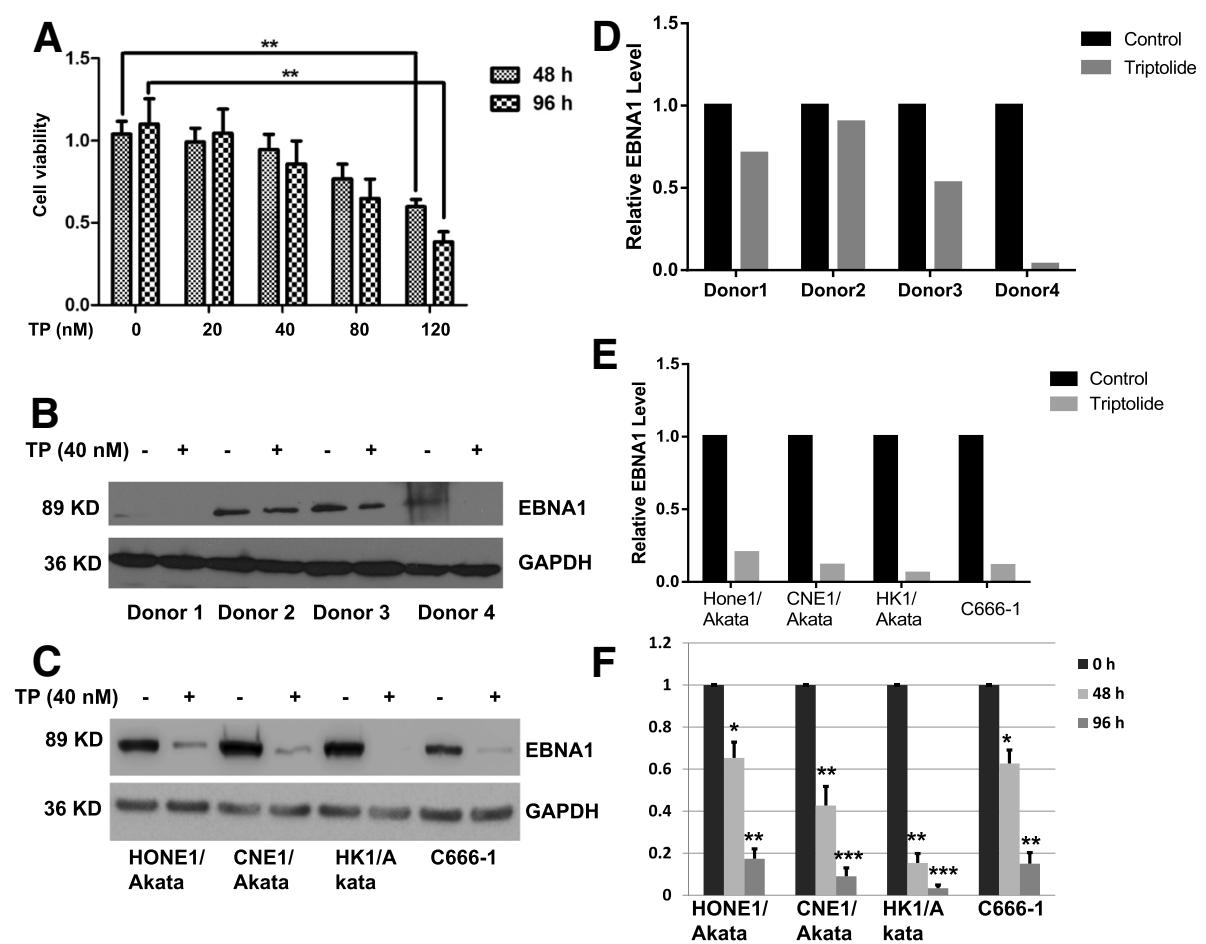

Fig. 7 TP at a non-toxic concentration decreases EBNA1 expression in PBMCs and NPC cells. PBMCs were isolated from EBV-positive donors and incubated with DMSO (0.01\%)or dose-dependent TP for 96 h. a Cell viability of PBMCs was detected by a CCK-8 assay. b PBMCs were treated with DMSO (0.01\%) or TP (40 nM) for 96 h. c HONE1/Akata, CNE1/Akata, HK1/Akata, and C666-1 cells were treated with DMSO (0.01\%) or TP $(40 \mathrm{nM})$ for $96 \mathrm{~h}$. Whole-cell extracts were prepared and subjected to Western blot analysis. Quantified analysis of EBNA1 expression in PBMCs (d) or NPC cell lines (e) were performed by Image J. f HONE1/Akata, CNE1/Akata, HK1/Akata and C666-1 cells were treated with DMSO (0.01\%) or TP $(40 \mathrm{nM})$ for 0,48 , and $96 \mathrm{~h}$. Cell viability of NPC cells were detected by a CCK-8 assay $\left({ }^{*}: P<0.05 ;{ }^{* *}: P<0.01\right.$; ${ }^{* *}$ : $P<0.001$ )

expression of Ki67 was associated with the nuclear distribution of EBNA1 in the NPC biopsies (Fig. 9a). As shown in Fig. 9b, EBNA1 was observed to locate in the cell nucleus in two biopsies from total 21 patients with high Ki67 expression. However, among 22 patients with low Ki67 expression, EBNA1 was expressed in both nucleus and cytoplasm in 8 patients (correlation coefficient $=4.45, p=0.037)$. These results suggested that EBNA1 was expressed in all EBV-positive NPC cancer cells and EBNA1 expression in nucleus probably indicates a low level of tumor growth progress.

\section{Discussion}

As reported, EBV infection is significantly associated with increased risks and poor prognosis of NPC [36]. The main function of EBNA1 is to regulate DNA synthesis of EBV and maintain mitotic segregation of EBV episomes to daughter cells [2-4]. Our previous study has proposed EBNA1 as a new molecular target for antiviral and anticancer treating strategies [33-35, 37]. In this study, we found that a traditional extract of herbal medicine, triptolide, effectively suppresses NPC cell growth and induces NPC apoptosis in vivo and in vitro. Besides, the low-toxicity triptolide decreased EBNA1 expression in EBV-positive
PBMCs from patients. Triptolide significantly decreased the expression of EBNA1 through a proteasome-ubiquitin pathway. Furthermore, we found that over-expression of EBNA1attenuates the caspase-9-dependent apoptosis induced by triptolide in NPC cells. In addition, EBNA1 was expressed in $100 \%$ NPC samples from patients and the nuclear distribution of EBNA1 indicated a low growth speed of NPC.

Triptolide is the most effective bioactive compound from Tripterygium wilfordii extracts [38]. Studies have suggested that triptolide killed cancer cells originated from blood, ovary, breast, lung prostate, and brain with $\mathrm{IC}_{50}$ values ranging from 2.5 to $50 \mathrm{nM}$ [12]. Here, our results showed that the $\mathrm{IC}_{50}$ of triptolide acting on NPC cells were from 1.12to $75.56 \mathrm{nM}$. Our previous study found that the cell cycle of EBV-positive B lymphoma cells was retarded with a reduction in S phase [27]. Here, we observed that the cell cycles of EBV-positive epithelial NPC cells treated with triptolide were ceased in $\mathrm{S}$ phase, which indicates that triptolide may encumber DNA synthesis of EBV-positive NPC cells. Some studies have suggested that triptolide induces caspase-8, 9 , and -3 activation and then activates downstream PARP in different cells [24, 25]. However, more evidence indicated that the essential apoptotic pathway is mitochondrial 


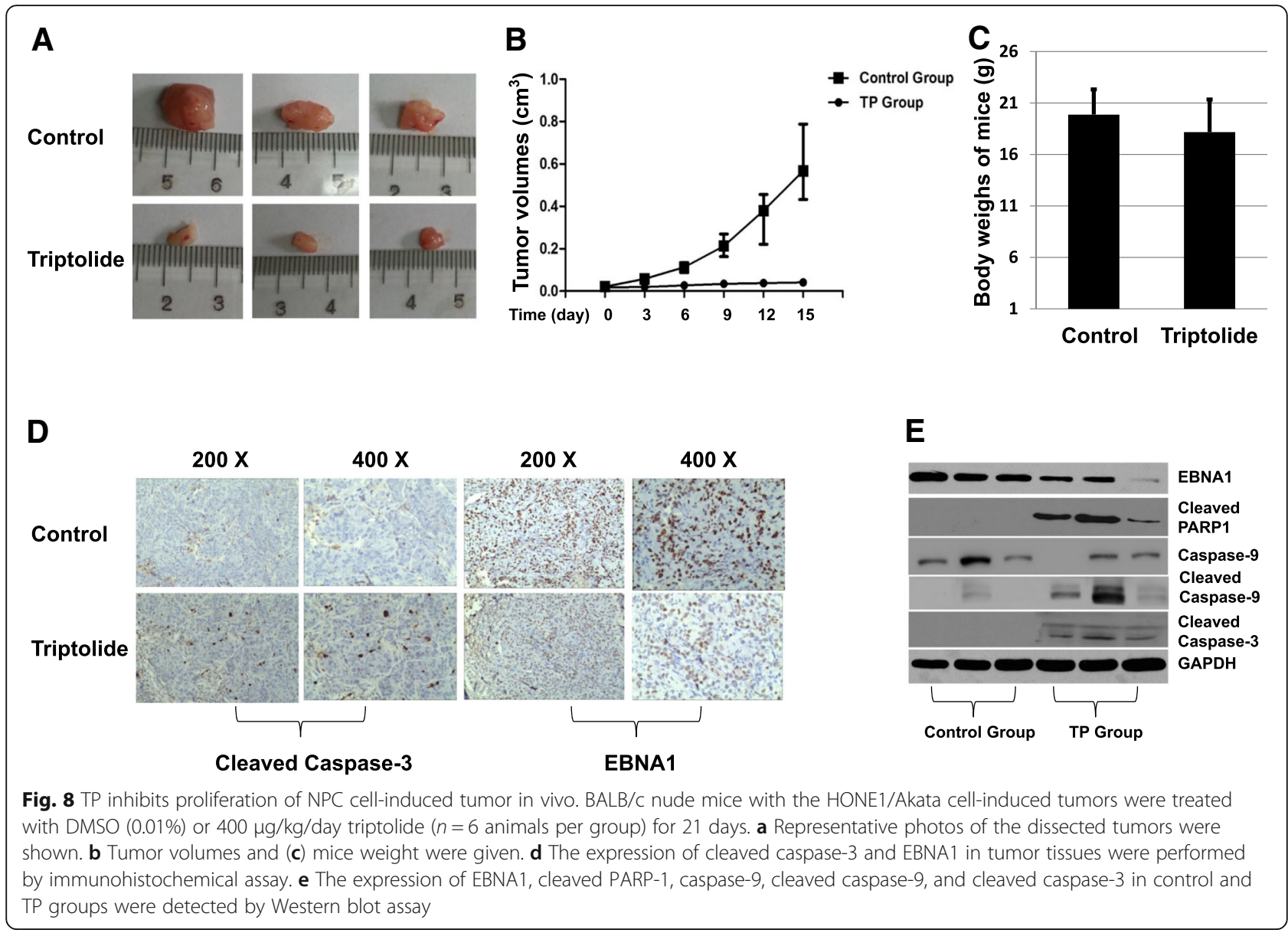

pathway rather than death receptor pathway [12, 24, 39, 40]. Our findings suggested that NPC cells were induced to apoptosis through a caspase- 9 pathway with triptolide treatment. P53 was reported to be necessary for triptolide to induce apoptosis in some cancer cells [41, 42]. Our results demonstrated that triptolide actives p53-dependent apoptotic pathway in NPC cells, which was similar to other cancer cells treated with triptolide [41, 42].

Triptolide was reported to cause transcription inhibition by targeting the largest subunit of RNA polymerase II (RPB1)-XPB and then induce apoptosis or immune/ inflammatory responses [26]. Our previous study found that the transcription level of LMP1 was inhibited by triptolide in B lymphoma cells [27]. Interestingly, we first found that triptolide increased the transcription levels of EBNA1 in NPC cells, but decreased protein level of EBNA1. Our previous study has certificated that triptolide inhibited LANA1, a critical latency antigen protein of $\mathrm{KSHV}$, in $\mathrm{KSHV}$-associated primary effusion lymphoma cells through proteasome-ubiquitin pathway [28]. Hence, we speculated whether triptolide has the similar effect on EBNA1. Although the exact mechanism

Table 1 The associations between EBNA1 distribution and sex, histopathological data, and KI67 expression

\begin{tabular}{|c|c|c|c|c|c|c|c|}
\hline \multirow[t]{2}{*}{ Criteria } & & \multirow{2}{*}{$\begin{array}{l}\text { Specimen } \\
\text { Nos. (\%) }\end{array}$} & \multicolumn{2}{|c|}{ EBNA1 Distribution (\%) } & \multirow[t]{2}{*}{$x^{2}$} & \multirow[t]{2}{*}{ Df } & \multirow[t]{2}{*}{$p$} \\
\hline & & & Nucleus $^{\mathrm{a}}$ & Cytoplasm & & & \\
\hline \multirow[t]{2}{*}{ Sex } & Female & $18(41.9)$ & $5(20)$ & $20(80)$ & 0.36 & 1 & 0.55 \\
\hline & Male & $25(58.1)$ & $5(27.8)$ & $13(72.2)$ & & & \\
\hline \multirow[t]{2}{*}{ Histological Types } & Differentiated & $17(39.5)$ & $5(29.4)$ & $12(70.6)$ & 0.6 & 1 & 0.44 \\
\hline & Undifferentiated & $26(60.5)$ & $5(19.2)$ & $21(80.8)$ & & & \\
\hline \multirow[t]{2}{*}{ KI67 expression } & High & $21(48.8)$ & $2(9.5)$ & $19(90.5)$ & 4.34 & 1 & $0.037^{b}$ \\
\hline & Low & $22(51.2)$ & $8(36.4)$ & $14(63.6)$ & & & \\
\hline
\end{tabular}

Note: ${ }^{\text {a }}$ EBNA1 expression in both nucleus and cytoplasm of NPC biopsy

${ }^{\mathrm{b}} p<0.05$ 


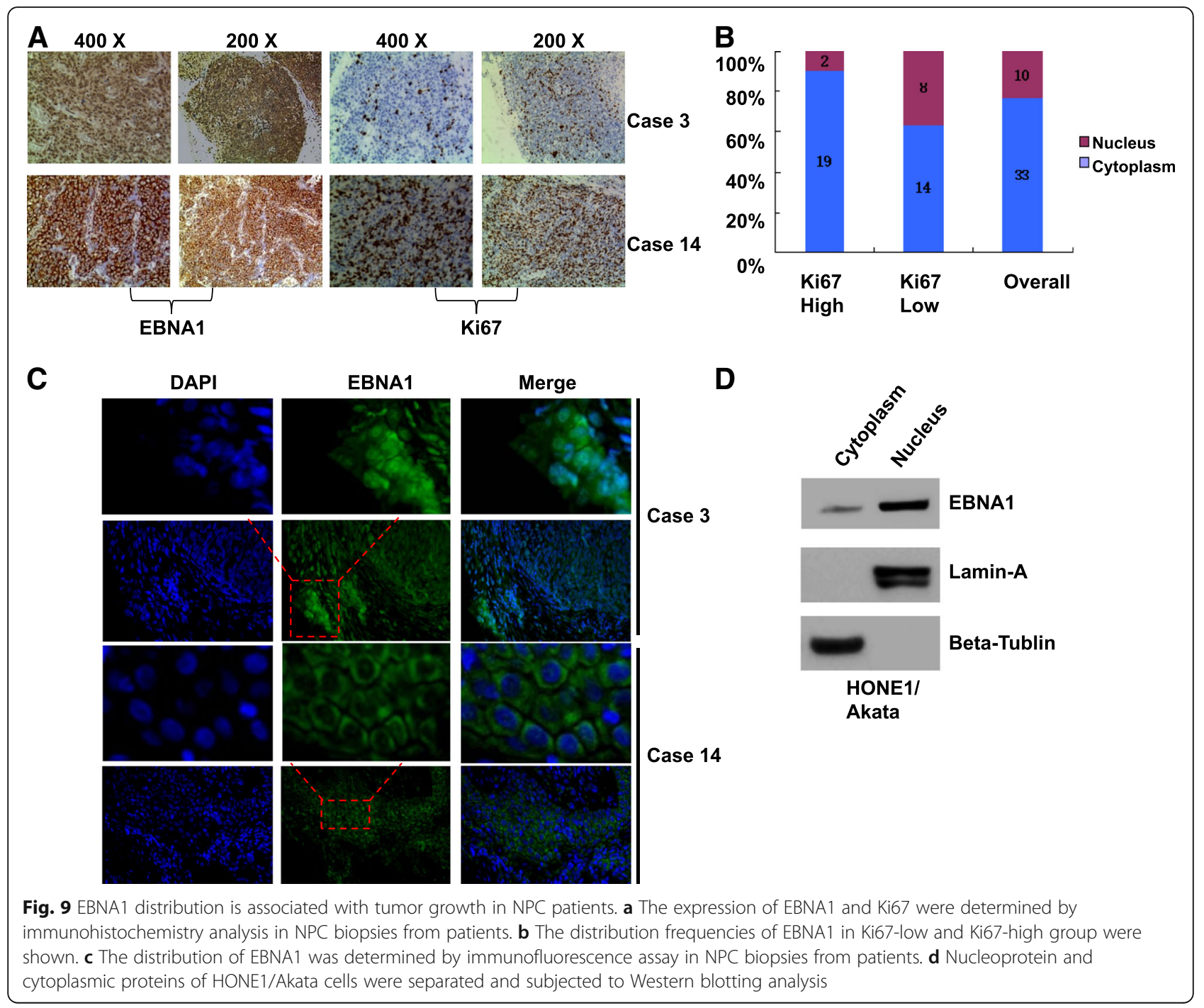

of how triptolide inhibits EBNA1expression still remains unclear, our results that triptolide induced EBNA1instability and degradation through proteasome-ubiquitin pathway suggested triptolide decreased EBNA1 expression through the post-translation pathway. Previous studies found that Gly-Ala repeat sequence plays important roles in inhibiting or abrogating EBNA1 from degradation by interfering its interaction with the $26 \mathrm{~S}$ proteasome [43, 44]. However, these conclusions were challenged when EBNA1 was artificially fused an Ub to its $\mathrm{N}$ terminus, it was efficiently and completely degraded which suggested that GAr can't prevent UbEBNA1 from being degraded. In addition, EBNA1 and EBNA1 $\triangle$ GAr had the similar half-life, which suggested that $\triangle$ GAr does not increased the stability of EBNA1 [45-47]. Interestingly, our results showed that high concentration and long-time treatment of MG-132 significantly increased EBNA1 expression, suggesting that EBNA1 degrades through proteasome-ubiquitin pathway, which is consistent with the finding of Chrysoula and his colleagues [46]. Similarly, the studies have reported that triptolide could induce degradations of various critical proteins from host or virus by promoting proteasome-ubiquitin pathway, including $\alpha$-synuclein [48] and Tat [49].

Apoptotic protease activating factor-1(Apaf1) and caspase-9 dependent mitochondrial apoptosis is activated to response to intracellular stress factors and ultimately leads to DNA damage and cell death. Our results firstly reported that EBNA1 inhibited the triptolide-induced apoptosis through inhibiting the caspase-9-dependent mitochondria apoptosis. Notably, our results showed that this inhibitory effect didn't rely on EBV genome and suggested that EBNA1 is an anti-apoptosis protein acting on mitochondria apoptosis pathway. V-val EBNA1 is the predominant subtype in NPC patients living in southeast China [31, 32]. Hence, we compared the anti-apoptosis effect of V-val with that of P-ala subtype of EBNA1. As speculated, 
V-val EBNA1 had the anti-apoptosis effect similar to P-ala EBNA1. Our previous studies have reported that EBNA1 could assist malignance cells to inhibit berberine [34] or 17-DMAG [33]-induced cancer cells death. Here, both P-ala and V-val EBNA1 attenuated the killing effects of triptolide on EBV-positive and EBVnegative NPC cell lines, suggesting that targeting on EBNA1 is a substantial strategy of treating EBVpositive NPC. It is a further reasonable interpretation how EBNA1 resists NPC cells death. However, the exact molecular mechanism how EBNA1 inhibits procaspase- 9 split into active caspase- 9 is still unclear. In addition, proteomic methods revealed that EBNA1 binds to a cellular ubiquitin-specific protease -USP7/ HAUSP. Because USP7can stabilize p53 and Mdm2 by interacting with these proteins, EBNA1 can competitively bind to the binding pocket in the N-terminal domain of USP7 and ultimately cause p53 destabilization in EBV-positive cells $[9,11]$. By inducing degradation of PML proteins, EBNA1 binds to USP7 and the host CK2 kinase and recruits these proteins to PML nuclear bodies and causes PML nuclear bodies disruption [9, 10, 50]. These mechanisms contribute to elucidating why EBV-positive cancer cells can resist DNA damage and apoptosis after treatment with DNA damaging agents, which may result in the development of NPC and gastric cancer.
The effect of triptolide on EBV-positive NPC cells was further confirmed by the animal experiments, since HONE1/Akata cell-induced xenograft tumors in BALB/c nude mice were significantly inhibited by triptolide. One group found that the positive rate of EBNA1 was about 92.5\% in Indian population [51]. Here, the expression of EBNA1in NPC biopsy of Chinese population was first investigated. Our present data showed a higher sensitivity $(100 \%)$ in EBV-positive tumor tissue of Chinese people, which suggested that detecting EBNA1 by immunohistochemistry assay may be a possible method to determine EBV infection in clinical application. Furthermore, our results showed that there were two statuses of EBNA1 expression. At all the biopsies, EBNA1 was expressed in cytoplasm in cancer cells. However, EBNA1 could be expressed in both cytoplasm and nucleus in some cases $(23.36 \%)$. These results which were consistent with previous studies suggested EBNA1 may exert different functions in tumor cells based on its various distributions [51, 52]. Importantly, the result that EBNA1 expressed in cells nuclear revealed a low proliferation speed of cancer cells. Limited studies have focused on the function of EBNA1 in cytoplasm. As a transcriptional factor, EBNA1 could inhibit NF- $\mathrm{kB}$ pathway in carcinoma cell lines by decreasing the phosphorylation of $\mathrm{IKK} \alpha / \beta$, and negatively modulate oncogenesis [8]. Ki67 expression is upregulated by EBNA1 in LCL

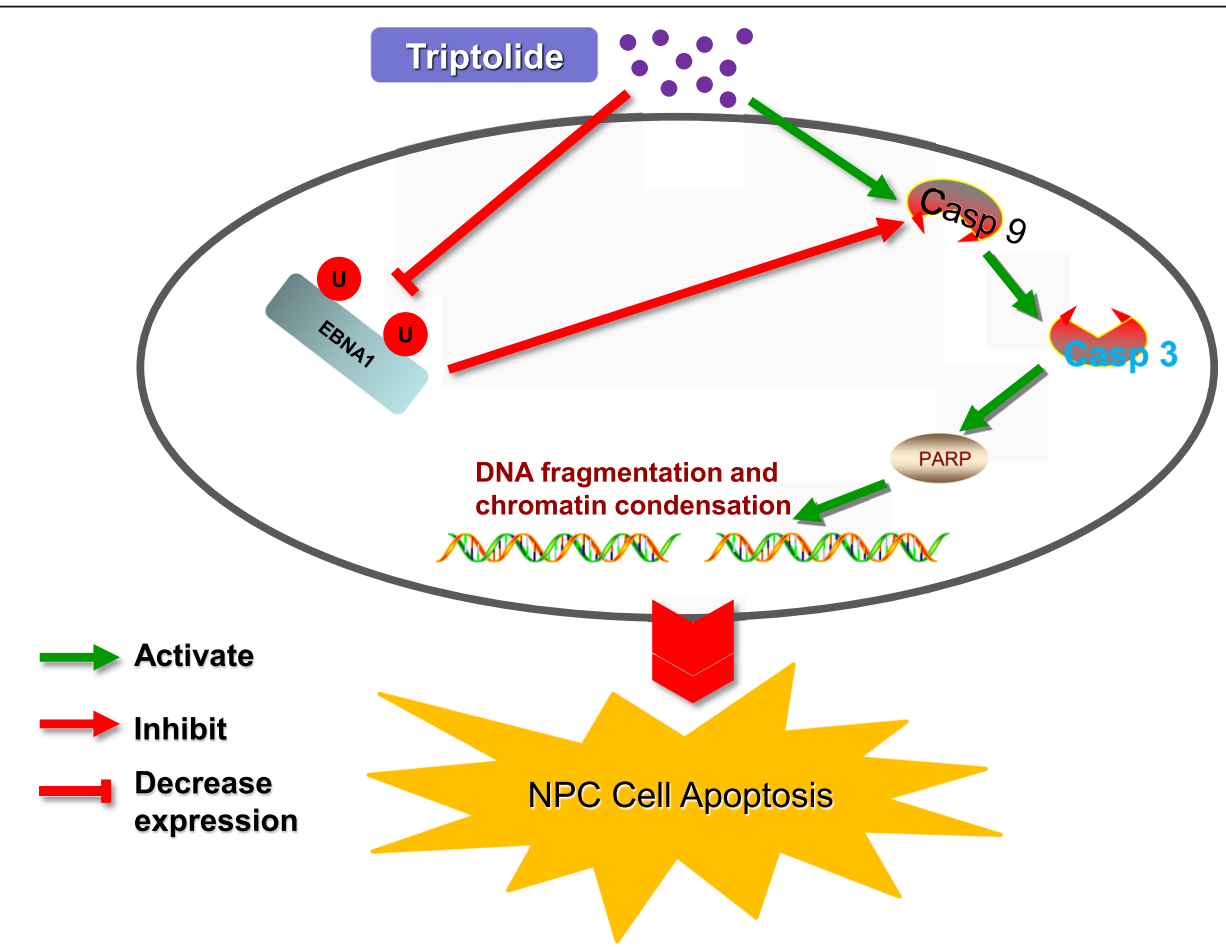

Fig. 10 Schematic depicts a possible mechanism of triptolide inducing apoptosis in EBV-positive NPC cell. The caspase-9 activation plays a critical role in triptolide-induced mitochondria apoptosis in NPC cells. Triptolide inhibits EBNA1 expression through contributing to the proteasomeubiquitin process and disturbing the stability of EBNA1, which promotes the activation of caspase-9, and induces the apoptotic effect of NPC cells 
cell lines [53]. It's consistent with our results that EBNA1 expressed in the nucleus was associated with a low tumor proliferation. Interestingly, the expression of EBNA1 in cytoplasm can only be found in cells of squamous cell carcinoma. In contrast, the expression of EBNA1 was found in nucleus of normal tissues. However, due to the restricted numbers of clinical samples, much more clinical samples deserve to be examined to confirm the phenomenon.

Our previous studies have suggested that low-toxicity 17-DMAG reduced the expression of EBNA1 in LCLs and inhibited the growth of tumor cells [33]. Here in this study, our results found that low-toxicity triptolide decreased EBNA1 expression in EBV-positive PBMCs. Although triptolide showed a super anti-tumor activity compared with adriamycin or aclacinomycin in clinical research, serious toxicities restricted the further clinical application of triptolide [12]. Overall, our results have indicated that triptolide inhibits EBNA1 expression at a low concentration, suppresses growth of NPC cells but has no significant toxic effect on PBMCs. These results suggested that a safe concentration of triptolide can be used in treatment of NPC in the future.

\section{Conclusion}

In summary, our data provide novel evidence that EBNA1 resists triptolide-induced NPC apoptosis through inhibiting the caspase-9 dependent apoptotic pathway, as depicted in Fig. 10. Triptolide decreases EBNA1 expression at a lowtoxicity dose and inhibits EBV-positive NPC cells growth in vivo and in vitro.

\section{Abbreviations \\ AP-1: Activator protein 1; Apaf1: Apoptotic protease activating factor-1; ATF2: Activating transcription factor; CCK-8: Cell Counting Kit-8; CHX: Cycloheximide; CK2: Casein kinase 2; DMSO: Dimethylsulfoxide; EBER: EBV-encoded small RNA; EBNA1: Epstein-Barr nuclear antigen 1; EBV: Epstein-Barr virus; IKK: I-kappaB kinase; KSHV: Kaposi's sarcoma- associated herpesvirus; LANA1: Latency-associated nuclear antigen 1; LMP: Latent membrane protein; NF-KB: Nuclear factor kappa B; NPC: Nasopharyngeal carcinoma; OriP: Latent origin of replication; PBMC: Peripheral blood mononuclear cell; PML: Promyelocytic leukemia; RPB1: RNA polymerase II; SB: Sodium butyrate; SP1: Specificity protein 1; TP: Triptolide; TPA: 12-O-tetradecanoylphorbol-13-acetate; USP: Ubiquitin- specific protease}

\section{Acknowledgments}

We thank S.W. Tsao (The University of Hong Kong, Hong Kong, China), Ya Cao (The University of Zhongnan, Chang Sha, China), Zhanqiu Yang (Wuhan University, Wuhan, China), HuiLi (Wuhan University, Wuhan, China) and Yixin Zeng (Sun Yat-Sen University, Guangzhou, China) for providing cell lines or plasmid.

\section{Consent for publications}

Not application.

\section{Funding}

The study was supported by the National Natural Science Foundation of China (No. 31270205), the Initiative Research Program of Wuhan University, China (No.410100020), and the advanced talent independent research program of Wuhan University, China (No. 410100011).

\section{Availability of data and materials}

All data generated or analyzed during this study are included in this published article.

\section{Authors' contributions}

XS designed the study; $H Z, Y L, C W, L L, H W, Y Z$ and $C L$ performed experiments; $\mathrm{HZ}$ and $\mathrm{XS}$ analyzed data and wrote the manuscript. All authors read and approved the final manuscript.

\section{Ethics approval and consent to participate}

The experiments of PBMC and tissue sample were approved by the Research and Ethical Committee of Wuhan University and were performed in accordance with the ethical standards laid down in the 1964 Declaration of Helsinki and its later amendments.

Our animal experiments were approved by the ABSL-3 animal lab at Wuhan University.

\section{Competing interests}

The authors declare that they have no competing interests.

\section{Publisher's Note}

Springer Nature remains neutral with regard to jurisdictional claims in published maps and institutional affiliations.

\section{Author details}

'The State Key Laboratory of Virology, Department of Pathogen Biology, School of Basic Medical Sciences, Hubei Province Key Laboratory of Allergy and Immune-related Diseases, Wuhan University, 185 Eastlake Road, Wuhan 430071, People's Republic of China. ${ }^{2}$ Department of Pathology, Renmin Hospital of Wuhan University, Wuhan University, Wuhan 430060, People's Republic of China. ${ }^{3}$ Department of Pathogen Biology, Weifang Medical University, Weifang 261053, People's Republic of China. ${ }^{4}$ Department of corneal disease, Weifang Eye Hospital, Weifang 261041, People's Republic of China.

Received: 28 March 2018 Accepted: 19 July 2018

Published online: 15 August 2018

References

1. Kieff ERA. Epstein-Barr virus and its replication. In: Fields' virology. 5th ed. Philadelphia: Lippincott Williams \& Wilkins; 2007. p. 2603-54.

2. Schepers A, Ritzi M, Bousset K, Kremmer E, Yates JL, Harwood J, Diffley JF, Hammerschmidt W. Human origin recognition complex binds to the region of the latent origin of DNA replication of Epstein-Barr virus. EMBO J. 2001; 20(16):4588-602.

3. Sears J, Kolman J, Wahl GM, Aiyar A. Metaphase chromosome tethering is necessary for the DNA synthesis and maintenance of oriP plasmids but is insufficient for transcription activation by Epstein-Barr nuclear antigen 1. J Virol. 2003;77(21):11767-80.

4. Nanbo A, Sugden A, Sugden B. The coupling of synthesis and partitioning of EBV's plasmid replicon is revealed in live cells. EMBO J. 2007;26(19):4252-62.

5. Gahn TA, Sugden B. An EBNA-1-dependent enhancer acts from a distance of 10 kilobase pairs to increase expression of the Epstein-Barr virus LMP gene. J Virol. 1995;69(4):2633-6.

6. Reisman D, Sugden B. trans activation of an Epstein-Barr viral transcriptional enhancer by the Epstein-Barr viral nuclear antigen 1. Mol Cell Biol. 1986; 6(11):3838-46.

7. O'Neil JD, Owen TJ, Wood VH, Date KL, Valentine R, Chukwuma MB, Arrand JR, Dawson CW, Young LS. Epstein-Barr virus-encoded EBNA1 modulates the AP-1 transcription factor pathway in nasopharyngeal carcinoma cells and enhances angiogenesis in vitro. J Gen Virol. 2008;89(Pt 11):2833-42.

8. Valentine R, Dawson CW, Hu C, Shah KM, Owen TJ, Date KL, Maia SP, Shao $J$, Arrand JR, Young LS, et al. Epstein-Barr virus-encoded EBNA1 inhibits the canonical NF-kappaB pathway in carcinoma cells by inhibiting IKK phosphorylation. Mol Cancer. 2010;9:1.

9. Holowaty MN, Zeghouf M, Wu H, Tellam J, Athanasopoulos V, Greenblatt J, Frappier L. Protein profiling with Epstein-Barr nuclear antigen-1 reveals an interaction with the herpesvirus-associated ubiquitin-specific protease HAUSP/USP7. J Biol Chem. 2003;278(32):29987-94. 
10. Sivachandran N, Cao JY, Frappier L. Epstein-Barr virus nuclear antigen 1 Hijacks the host kinase CK2 to disrupt PML nuclear bodies. J Virol. 2010; 84(21):11113-23

11. Saridakis V, Sheng Y, Sarkari F, Holowaty MN, Shire K, Nguyen T, Zhang RG, Liao J, Lee W, Edwards AM, et al. Structure of the p53 binding domain of HAUSP/USP7 bound to Epstein-Barr nuclear antigen 1 implications for EBVmediated immortalization. Mol cell. 2005;18(1):25-36.

12. Zhou ZL, Yang YX, Ding J, Li YC, Miao ZH. Triptolide: structural modifications, structure-activity relationships, bioactivities, clinical development and mechanisms. Nat Prod Rep. 2012;29(4):457-75.

13. Arora N, Alsaied O, Dauer P, Majumder K, Modi S, Giri B, Dudeja V, Banerjee S, Von Hoff D, Saluja A. Downregulation of Sp1 by Minnelide leads to decrease in HSP70 and decrease in tumor burden of gastric cancer. PloS One. 2017;12(2):e0171827.

14. Wang W, Yang S, Su Y, Xiao Z, Wang C, Li X, Lin L, Fenton BM, Paoni SF, Ding I, et al. Enhanced antitumor effect of combined triptolide and ionizing radiation. Clin Cancer Res. 2007:13(16):4891-9.

15. Ding X, Zhou X, Zhang H, Qing J, Qiang H, Zhou G. Triptolide augments the effects of 5-lipoxygenase RNA interference in suppressing pancreatic tumor growth in a xenograft mouse model. Cancer Chemother Pharmacol. 2012; 69(1):253-61.

16. Banerjee S, Sangwan V, McGinn O, Chugh R, Dudeja V, Vickers SM, Saluja AK. Triptolide-induced cell death in pancreatic cancer is mediated by O-GlcNAc modification of transcription factor Sp1. J Biol Chem. 2013;288(47):33927-38.

17. Pan J. RNA polymerase - an important molecular target of triptolide in cancer cells. Cancer letters. 2010;292(2):149-52.

18. Tang XY, Zhu YQ, Tao WH, Wei B, Lin XL. Synergistic effect of triptolide combined with 5-fluorouracil on colon carcinoma. Postgrad Med J. 2007; 83(979):338-43.

19. Yuan S, Wang L, Chen X, Fan B, Yuan Q, Zhang H, Yang D, Wang S. Triptolide inhibits the migration and invasion of human prostate cancer cells via Caveolin-1/CD147/MMPs pathway. Biomed Pharmacother. 2016;84: $1776-82$.

20. Shi X, Jin Y, Cheng C, Zhang H, Zou W, Zheng Q, Lu Z, Chen Q, Lai Y, Pan J. Triptolide inhibits Bcr-Abl transcription and induces apoptosis in STI571resistant chronic myelogenous leukemia cells harboring T315I mutation. Clin Cancer Res. 2009:15(5):1686-97.

21. Shamon LA, Pezzuto JM, Graves JM, Mehta RR, Wangcharoentrakul S, Sangsuwan R, Chaichana S, Tuchinda P, Cleason P, Reutrakul V. Evaluation of the mutagenic, cytotoxic, and antitumor potential of triptolide, a highly oxygenated diterpene isolated from Tripterygium wilfordii. Cancer letters. 1997;112(1):113-7.

22. Yang S, Chen J, Guo Z, Xu XM, Wang L, Pei XF, Yang J, Underhill CB, Zhang $L$. Triptolide inhibits the growth and metastasis of solid tumors. Mol Cancer Ther. 2003;2(1):65-72.

23. Westfall SD, Nilsson EE, Skinner MK. Role of triptolide as an adjunct chemotherapy for ovarian cancer. Chemotherapy. 2008;54(1):67-76.

24. Carter BZ, Mak DH, Schober WD, McQueen T, Harris D, Estrov Z, Evans $\mathrm{RL}$, Andreeff M. Triptolide induces caspase-dependent cell death mediated via the mitochondrial pathway in leukemic cells. Blood. 2006;108(2):630-7.

25. Yang $M$, Huang J, Pan $\mathrm{HZ}$, Jin J. Triptolide overcomes dexamethasone resistance and enhanced PS-341-induced apoptosis via PI3k/Akt/NFkappaB pathways in human multiple myeloma cells. Int J Mol Med. 2008;22(4):489-96

26. Titov DV, Gilman B, He QL, Bhat S, Low WK, Dang Y, Smeaton M, Demain $A L$, Miller PS, Kugel JF, et al. XPB, a subunit of TFIIH, is a target of the natural product triptolide. Nat Chem Biol. 2011;7(3):182-8.

27. Zhou H, Guo W, Long C, Wang H, Wang J, Sun X. Triptolide inhibits proliferation of Epstein-Barr virus-positive B lymphocytes by downregulating expression of a viral protein LMP1. Biochem Biophys Res Commun. 2015;456(3):815-20.

28. Long C, Guo W, Zhou H, Wang J, Wang H, Sun X. Triptolide decreases expression of latency-associated nuclear antigen 1 and reduces viral titers in Kaposi's sarcoma-associated and herpesvirus-related primary effusion lymphoma cells. Int J Oncol. 2016;48(4):1519-30.

29. Mai SJ, Ooka T, Li DJ, Zeng MS, Jiang RC, Yu XJ, Zhang RH, Chen SP, Zeng YX. Functional advantage of NPC-related V-val subtype of Epstein-Barr virus nuclear antigen 1 compared with prototype in epithelial cell line. Oncol Rep. 2007;17(1):141-6.
30. Yin Q, Flemington EK. siRNAs against the Epstein Barr virus latency replication factor, EBNA1, inhibit its function and growth of EBV-dependent tumor cells. Virology. 2006;346(2):385-93.

31. Zhang XS, Wang HH, Hu LF, Li A, Zhang $\mathrm{RH}$, Mai HQ, Xia JC, Chen LZ, Zeng YX. V-val subtype of Epstein-Barr virus nuclear antigen 1 preferentially exists in biopsies of nasopharyngeal carcinoma. Cancer letters. 2004;211(1):11-8.

32. Do NV, Ingemar E, Phi PT, Jenny A, Chinh TT, Zeng Y, Hu L. A major EBNA1 variant from Asian EBV isolates shows enhanced transcriptional activity compared to prototype B95.8. Virus Res. 2008;132(1-2):15-24.

33. Sun X, Barlow EA, Ma S, Hagemeier SR, Duellman SJ, Burgess RR, Tellam J, Khanna R, Kenney SC. Hsp90 inhibitors block outgrowth of EBV-infected malignant cells in vitro and in vivo through an EBNA1-dependent mechanism. Proc Natl Acad Sci U S A. 2010;107(7):3146-51.

34. Wang C, Wang H, Zhang Y, Guo W, Long C, Wang J, Liu L, Sun X. Berberine inhibits the proliferation of human nasopharyngeal carcinoma cells via an Epstein-Barr virus nuclear antigen 1-dependent mechanism. Oncol Rep. 2017;37(4):2109-20.

35. Zhang Y, Wang H, Liu Y, Wang C, Wang J, Long C, Guo W, Sun X. Baicalein inhibits growth of Epstein-Barr virus-positive nasopharyngeal carcinoma by repressing the activity of EBNA1 Q-promoter. Biomed Pharmacother. 2018; 102:1003-14.

36. Liu TB, Zheng ZH, Pan J, Pan LL, Chen LH. Prognostic role of plasma Epstein-Barr virus DNA load for nasopharyngeal carcinoma: a meta-analysis. Clin Invest Med. 2017;40(1):E1-E12.

37. Wang H, Bu L, Wang C, Zhang Y, Zhou H, Zhang X, Guo W, Long C, Guo D, Sun $\mathrm{X}$. The Hsp70 inhibitor 2-phenylethynesulfonamide inhibits replication and carcinogenicity of Epstein-Barr virus by inhibiting the molecular chaperone function of Hsp70. Cell Death Dis. 2018;9(7):734.

38. Kupchan SM, Court WA, Dailey RG Jr, Gilmore CJ, Bryan RF. Triptolide and tripdiolide, novel antileukemic diterpenoid triepoxides from Tripterygium wilfordii. J Am Chem Soc. 1972;94(20):7194-5.

39. Cheng X, Shi W, Zhao C, Zhang D, Liang P, Wang G, Lu L. Triptolide sensitizes human breast cancer cells to tumor necrosis factoralphainduced apoptosis by inhibiting activation of the nuclear factorkappaB pathway. Mol Med Rep. 2016;13(4):3257-64.

40. Yan X, Ke XX, Zhao H, Huang M, Hu R, Cui H. Triptolide inhibits cell proliferation and tumorigenicity of human neuroblastoma cells. Mol Med Rep. 2015;11(2):791-6.

41. Jiang $X H$, Wong $B C$, Lin MC, Zhu GH, Kung HF, Jiang SH, Yang D, Lam SK. Functional p53 is required for triptolide-induced apoptosis and AP-1 and nuclear factor-kappaB activation in gastric cancer cells. Oncogene. 2001; 20(55):8009-18.

42. Chang WT, Kang JJ, Lee KY, Wei K, Anderson E, Gotmare S, Ross JA, Rosen GD. Triptolide and chemotherapy cooperate in tumor cell apoptosis. A role for the p53 pathway. J Biol Chem. 2001;276(3):2221-7.

43. Levitskaya J, Sharipo A, Leonchiks A, Ciechanover A, Masucci MG. Inhibition of ubiquitin/proteasome-dependent protein degradation by the Gly-Ala repeat domain of the Epstein-Barr virus nuclear antigen 1. Proc Natl Acad Sci U S A. 1997;94(23):12616-21.

44. Sharipo A, Imreh $M$, Leonchiks A, Imreh S, Masucci MG. A minimal glycinealanine repeat prevents the interaction of ubiquitinated I kappaB alpha with the proteasome: a new mechanism for selective inhibition of proteolysis. Nat Med. 1998;4(8):939-44.

45. Daskalogianni C, Apcher S, Candeias MM, Naski N, Calvo F, Fahraeus R. Gly-Ala repeats induce position- and substrate-specific regulation of $26 \mathrm{~S}$ proteasomedependent partial processing. J Biol Chem. 2008;283(44):30090-100.

46. Dantuma NP, Heessen S, Lindsten K, Jellne M, Masucci MG. Inhibition of proteasomal degradation by the gly-Ala repeat of Epstein-Barr virus is influenced by the length of the repeat and the strength of the degradation signal. Proc Natl Acad Sci U S A. 2000;97(15):8381-5.

47. Tellam J, Sherritt M, Thomson S, Tellam R, Moss DJ, Burrows SR, Wiertz E, Khanna R. Targeting of EBNA1 for rapid intracellular degradation overrides the inhibitory effects of the Gly-Ala repeat domain and restores CD8+ T cell recognition. J Biol Chem. 2001;276(36):33353-60.

48. Hu G, Gong X, Wang L, Liu M, Liu Y, Fu X, Wang W, Zhang T, Wang X Triptolide Promotes the Clearance of alpha-Synuclein by Enhancing Autophagy in Neuronal Cells. Mol Neurobiol. 2017;54(3):2361-72.

49. Wan Z, Chen X. Triptolide inhibits human immunodeficiency virus type 1 replication by promoting proteasomal degradation of Tat protein. Retrovirology. 2014;11:88 
50. Sivachandran N, Sarkari F, Frappier L. Epstein-Barr nuclear antigen 1 contributes to nasopharyngeal carcinoma through disruption of PML nuclear bodies. PLoS pathogens. 2008;4(10):e1000170.

51. Borthakur P, Kataki K, Keppen C, Khamo V, Medhi S, Deka M. Expression of Epstein Barr Virus Encoded EBNA1 and LMP1 Oncoproteins in Nasopharyngeal Carcinomas from Northeast India. Asian Pac J Cancer Prev. 2016;17(7):3411-6.

52. Surono A, Hariwiyanto B, Samodra E. Detection of Epstein-Barr and Human Papilloma Viruses in the Middle Ear Squamous Cell Carcinoma. Indian J Otolaryngol Head Neck surg. 2018;70(1):66-70.

53. AlQarni S, Al-Sheikh Y, Campbell D, Drotar M, Hannigan A, Boyle S, Herzyk P, Kossenkov A, Armfield K, Jamieson L, et al. Lymphomas driven by EpsteinBarr virus nuclear antigen-1 (EBNA1) are dependant upon Mdm2. Oncogene. 2018;37(29):3998-4012.

- fast, convenient online submission

- thorough peer review by experienced researchers in your field

- rapid publication on acceptance

- support for research data, including large and complex data types

- gold Open Access which fosters wider collaboration and increased citations

- maximum visibility for your research: over $100 \mathrm{M}$ website views per year

At BMC, research is always in progress.

Learn more biomedcentral.com/submissions 